Backlogs and litigation rates: Testing congestion equilibrium across European judiciaries

Peer-reviewed author version

BIELEN, Samantha; PEETERS, Ludo; MARNEFFE, Wim \& VEREECK, Lode (2017) Backlogs and litigation rates: Testing congestion equilibrium across European judiciaries. In: International review of law and economics, 53, p. 9-22.

DOI: 10.1016/j.irle.2017.09.002

Handle: http://hdl.handle.net/1942/24927 


\title{
Backlogs and Litigation Rates: Testing Congestion Equilibrium Across European Judiciaries
}

\author{
Samantha Bielen ${ }^{1}$ \\ Ludo Peeters ${ }^{2}$ \\ Wim Marneffe ${ }^{3}$ \\ Lode Vereeck $^{4}$
}

\begin{abstract}
To address the problem of court backlogs, policymakers in many countries have been pursuing reforms to reduce case disposition times and the demand for litigation. Yet Priest's (1989) congestion-equilibrium theory states that reforms aimed at reducing court delays are offset by an increased tendency to litigate. To test the congestion-equilibrium hypothesis, we use biennial panel data from 36 European countries over the period 2006-2012. Specifically, we estimate (i) a repeated cross-section model using conventional (pooled) OLS, (ii) a standard (static) random-effects panel data model, and (iii) a (static) random effects model using the new method of unconditional quantile regression (UQR) to examine the countrylevel relationship between litigation rates and court backlogs (measured by the number of pending cases per judge in each country). In accordance with the congestion equilibrium hypothesis, the UQR estimates suggest a negative impact of court backlogs on litigation rates but only in highly litigious countries, insofar as the latter experience a high degree of judicial independence. This shows the need for custom-tailored policy approaches to tackling court delay based on countries' existing litigation rates.
\end{abstract}

\section{Keywords}

Congestion equilibrium; court backlog; litigation; judicial independence; unconditional quantile regression.

\section{JEL Classifications}

C31; K00, K410.

\section{Acknowledgments}

Samantha Bielen would like to thank the Research Foundation Flanders for funding her postdoctoral mandate with grant number $12 \mathrm{~S} 3117 \mathrm{~N}$.

${ }^{1}$ Corresponding author: Hasselt University, Faculty of Applied Economics, Martelarenlaan 42, 3500 Hasselt, Belgium. E-mail: samantha.bielen@uhasselt.be. Telephone: +32 11268759.

${ }^{2}$ Hasselt University, Faculty of Applied Economics, Martelarenlaan 42, 3500 Hasselt, Belgium, and Autonomous University of Madrid, Faculty of Economics and Business, C/ Francisco Tomás y Valiente 5, 28049, Madrid, Spain.

E-mail: ludo.peeters@uhasselt.be; ludo.peeters@inv.uam.es.

${ }^{3}$ Hasselt University, Faculty of Applied Economics, Martelarenlaan 42, 3500 Hasselt, Belgium.

E-mail: wim.marneffe@uhasselt.be.

${ }^{4}$ Hasselt University, Faculty of Applied Economics, Martelarenlaan 42, 3500 Hasselt, Belgium.

E-mail: lode.vereeck@uhasselt.be 


\section{Introduction}

Countries around the world are enduring a growing propensity to litigate (Clemenz and Gugler 2000, Yates, Davis and Glick 2001, Ginsburg and Hoetker 2006). This increased demand for litigation is likely to exceed its supply, as the latter critically depends on the available "judge time", which is fixed in the short run. Moreover, judiciaries tend to rely on waiting lists rather than on a price mechanism as a rationing device (Posner 2014). In numerous countries, the resulting court backlogs have reached alarming levels, thus eroding individual and property rights, hampering economic progress and, in some instances, even violating human rights (Buscaglia and Dakolias 1999).

To address the problem of court backlogs, policymakers have been drafting reforms to improve timeliness and reducing the demand for litigation. However, most countries remain unsuccessful in significantly reducing court congestion and delay. In his seminal paper, Priest (1989) argued that the existence of a congestion equilibrium could account for the fact that reforms aimed at reducing litigation delays appear to be only temporarily effective: "The congestion equilibrium hypothesis compels a rethinking of the litigation delay problem. Most importantly, it demonstrates that litigants themselves, as they negotiate over settlement or litigation, centrally determine the extent of delay. [...] Changes in procedures or management, like changes in litigation volume, will affect the extent of delay, but they will also affect the settlement negotiations of the parties, generating the equilibrium. [...] The equilibrium concept implies that the parties' litigation decisions will serve to offset the effects of congestion reform." Put differently, if court congestion declines when delay-reducing measures are put in place, more disputes proceed to court and court congestion increases back toward the equilibrium level. A similar phenomenon, the Braess (1968) paradox, is observed in traffic where new road infrastructure lowers congestion in the short run, but in turn also induces new traffic. As a result, congestion is restored up to the equilibrium level. Nevertheless, note that the congestion equilibrium hypothesis does not imply that reforms will have no impact whatsoever. An effective policy measure may well generate a new and lower equilibrium level of congestion. Many authors have discussed the equilibrium hypothesis on court delay. Yet, to this date clear and robust empirical validation of this hypothesis is still missing.

Our contribution to the literature is twofold. Firstly, we exploit a biennial dataset for 36 European countries over the period 2006-2012 to examine the relationship between litigation rates and court backlogs across national judicial systems, where the latter are measured by the number of pending (unresolved) court cases per judge. In other words, we test the congestion equilibrium hypothesis for 36 European judiciaries: does a decrease in court backlogs, ceteris paribus, increase litigation rates?

Secondly, our study aims at examining whether differences in the relationship between litigation rates and court backlogs exist across national jurisdictions. We examine whether there are non-uniform responses to changing backlog numbers among the countries in the sample population. For instance, high-litigation jurisdictions (countries that are most in need of reducing litigiousness) may respond differently as compared to low-litigation jurisdictions (countries where reducing litigiousness is needed least). To achieve our goal, we use the method of unconditional quantile regression (UQR), recently introduced by Firpo, Fortin, and Lemieux (2009; hereafter denoted by FFL). ${ }^{1}$ This new UQR method allows for testing the existence of a congestion equilibrium at different quantiles of the distribution of litigation rates across the sampled countries, where low- and high-litigation countries are positioned in the lower and upper part of the litigation-rate distribution, respectively. The most important advantage of the UQR estimator over conventional mean estimators (such as OLS or traditional panel-data methods) is its ability to allow us to see how the entire distribution of litigation rates in the population changes when a given covariate changes, rather than just looking at how the mean of the distribution changes - i.e., the UQR estimator allows us to go beyond the average response of the dependent variable (Porter 2015, p. 338). Given the heterogeneous world we live in, we may see that a congestion equilibrium emerges in some countries but not in others. To the best of our knowledge, this paper is the first one employing this new UQR estimator in the area of litigation research.

Previewing our UQR results, some important regularities stand out. We find no evidence of a congestion equilibrium in lightly to moderately litigious jurisdictions. Conversely, a strong inverse relationship between court backlogs and litigation

\footnotetext{
${ }^{1}$ The UQR method should be clearly distinguished from the widely-used method of conditional quantile regression (CQR), developed by Koenker and Bassett (1978).
} 
is found only in the upper part of the litigation-rate distribution (i.e. the heavily litigious jurisdictions), though insofar as the countries experience a high degree of judicial independence.

The remainder of the paper is organized as follows. The next section spells out the decision-making process of a rational individual to start a lawsuit. Section 3 expands on the data used and the key variables included in our study, and provides basic descriptive statistics, followed by the specification of the empirical model. Section 4 describes the unconditional quantile regression ( $U Q R)$ method used for the estimations. Section 5 discusses the empirical results as well as some robustness checks and endogeneity concerns. Section 6 summarizes our main findings and formulates some conclusions and policy implications.

\section{Theoretical Background}

This section provides a brief overview of existing literature dealing with the decision to start a lawsuit, along with some background information which may help the reader in appreciating the empirical results presented in the following sections. For a more elaborate review of the literature, see Bielen, Marneffe, and Vereeck (2015).

Law and economics literature states that the theoretical decision-making process of a rational plaintiff to start a lawsuit encompasses three aspects: the legal costs, the value of the judgment and the likelihood of a court decision in his favor. However, little empirical evidence exists of the specific impact of these three aspects on litigation rates. When explaining the demand for litigation by means of empirical analyses, most scholars examine phenomena that influence the occurrence of a conflict (such as the effect of the population density, the number of road accidents, the income per capita, the GDP, the degree of urbanization, the employment rate, the number of enterprises, the poverty rate, etc.) on the number of lawsuits (Murrell 2001, D'Agostino, Sironi and Sobbrio 2012, Bachmeier, Gaughan and Swanson 2004, Mora-Sanguinetti and Garoupa 2015). While the existing literature regarding the functioning of judiciaries focuses mostly on measuring court performances and court efficiency (Kittelsen and Førsund 1992, Rosales-López 2008, Dimitrova-Grajzl et al. 2012, Christensen and Szmer 2012, Di Vita 2010), an empirical investigation of the impact of court delay on the recourse to justice in Europe does not exist to date.

A rational plaintiff will decide to file suit based on the outcome of a recursively solved sequence game that weighs present costs (e.g. litigation costs) against expected future benefits. A risk neutral plaintiff will only file suit if the expected utility from pursuing the suit exceeds the utility of settlement (Heaton and Helland 2011)2:

$$
\int U\left(a e^{-r t}\right) d F(a)>u[c(t)]
$$

Where $a$ represents the ultimate payout awarded by the judge, net from any costs (such as lawyer fees), $r$ is the discount rate and $t$ is the time to court resolution. $c(t)$ is the settlement amount the plaintiff could receive today. Accounting for time is crucial, since several authors have concluded that, theoretically, court delay influences the plaintiff's decision process (Priest 1989, Gravelle 1990, Vereeck and Mühl 2000). The hypothesis that court delay reduces litigation emerges from the fact that rational plaintiffs weigh uncertain future benefits against known current litigation costs. Therefore, from the plaintiff's perspective the net value of $a$ decreases with a discount factor of time, $\mathrm{e}^{- \text {rt }}$. $^{3}$

Gravelle (1990) shows that the negative relationship between litigation and delay implies that the latter can function as a rationing mechanism since it reduces litigation until it equals the capacity of the courts. However, Priest (1989) concludes from this negative dynamic relationship that there is likely to be an equilibrium level of delay within jurisdictions. As Gravelle (1990) argues, when court delay increases, the expected value of a judgment diminishes and consequently less lawsuits are likely to be filed. Priest (1989) argues that this inverse relationship between delay and the probability of litigation suggests that there is likely to be some equilibrium level of delay within any jurisdiction. The results of Chappe (2012) seem to be consistent with those of Priest (1989): "the effects of [...] measures aimed at decreasing court caseloads (higher fees, lower awards, settlement) but also for measures to increase court capacity [...] may be offset by a resulting increase in the demand

\footnotetext{
${ }^{2}$ Since $a$ is the ultimate payout, net from any costs (such as lawyer fees), this model is robust to fee allocation rules. The majority of the countries in our sample uses a loser pays rule, but there are some exceptions (e.g. Czech Republic, Denmark, Estonia, Greece, Poland, Spain and Sweden).

${ }^{3}$ This depreciation can be (partly) avoided by means of legal interests, which is not accounted for in the present analysis.
} 
for litigation". In sum, discouraging litigation might reduce litigation rates in the short run, but this effect is possibly offset in the long run by an increase in litigation due to reduced costs of delay. Similarly, augmenting the capacity of courts might not decrease delay in the long run.

\section{Data and Model Specification}

This section describes the data sources used to test the congestion equilibrium hypothesis for 36 European countries. Subsequently, we elaborate on the variables used in the analysis and the specification of the regression models.

\subsection{Data and Data Sources}

This paper uses country-level data to investigate the impact of pending cases on litigation. Assembling a dataset covering different countries is a challenging task, given the paucity of comparable data. Nonetheless, we were able to construct a usable (unbalanced) panel dataset containing biennial data for 36 European countries for the years 2006, 2008, 2010, and 2012. ${ }^{4}$ The data were compiled from two major sources: (a) the European Commission for the Efficiency of Justice (CEPEJ 2008, 2010, 2012, 2014), and (b) the World Economic Forum (2013). Although the CEPEJ data have been frequently used in earlier studies concerning the court system (see, e.g. Buonanno and Galizzi 2014, Cross and Donelson 2010, Palumbo et al. 2013, Ramello and Voigt 2012, Voigt and El-Bialy 2014, Ippoliti, Melcarne and Ramello 2015a, b, Roussey and Deffains 2012), we are not aware of any other study using these data in explaining litigation rates across countries.

Although our dataset has unique and interesting features, it is worth mentioning some limitations that are related to the lack of consistent (comparable) country-level data. These limitations make it hard to control for certain mechanisms that are likely to ration the market for litigation. For instance, from Barzel (1974) we know that litigation markets can be rationed by either price or by waiting. In our empirical model, we include variables that capture the "waiting" part. As to the "price" component, however, reliable data are missing. Although analyzing the impact of price (i.e., litigation costs) is worthwhile, one might argue that in a short time span such as our dataset, it is unlikely that legal costs have changed significantly (hence, they are captured by the fixed effects). Additionally, most scholars argue that litigation is usually not rationed by price but rather by waiting (Gravelle 1989, Vereeck and Mühl 2000, Posner 2014), since most countries are unwilling to reduce access to the courts for low income parties. Another variable that is missing in our analysis is the "market structure" for dispute resolution. In some countries, public courts do not face any competition at all, while in other countries they have to compete against alternative dispute resolution (ADR) mechanisms such as private arbitration or mediation (Doornik 2014). Unfortunately, though, we were not able to collect usable data on the available methods of ADR and their application.

\subsection{Variables and Descriptive Statistics}

Country-level litigation rate is the dependent variable in our empirical model. This variable measures the annual number of incoming (civil and commercial) case filings per 10,000 inhabitants, which reflects the effective demand on the court system in each country.

Among our key independent variables we have two indicators that measure different aspects of judicial efficiency and are both related to timeliness, namely pending cases (PEN) and resolved cases (RES). The annual number of cases pending per judge (PEN) is an indicator of the extent to which courts are able to meet national demand for dispute resolution (Buscaglia and Dakolias 1999). Therefore, it is a good measure for court backlogs. Following Priest (1989), we hypothesize that a decrease in court backlogs, ceteris paribus, increases litigation. We include the number of resolved cases per judge (RES) to measure judge productivity and expect a positive relationship with litigation rates. We also account for a country's judicial independence (IND), using the 7-point scale measure of the World Economic Forum. ${ }^{5}$ However, the effect of judicial independence can be ambiguous. It is imaginable that independent courts, where verdicts might be less predictable because judges cannot be bribed or do not favor a certain group of people, repel parties to file suit and induce them to settle or use alternative dispute resolution rather than await a "random" court judgment. Yet, it is equally imaginable that less

\footnotetext{
${ }^{4} \mathrm{~A}$ list of the countries included in our dataset is given in Appendix 1.

${ }^{5}$ Question asked in the Executive Opinion Survey (World Economic Forum): "To what extent is the judiciary in your country independent from influences of members of government, citizens and firms?".
} 
independent courts increase the subjective winning probabilities of parties (i.e., relative optimism), encouraging the recourse to justice.

Following existing empirical literature, we include per-capita GDP as a control variable. We enter both GDP per capita and its squared value because a quadratic form provides a more flexible specification of the empirical model. The motivation of including this economic factor as a control is fourfold. First, in wealthier countries, parties find it easier to fulfill their obligations, fewer contracts are broken and creditors are presumably more patient. Second, a higher GDP per capita not only implies a higher number of transactions but also more complex transactions, which in turn augments the potential for conflicts (Hanssen 1999, Posner 1997, Clemenz and Gugler 2000, Ginsburg and Hoetker 2006, Jacobi 2009). Third, GDP is likely to impact civil cases that are not related to contracts. ${ }^{6}$ For example, commercial and intellectual property lawsuits are presumably linked to the performance of the economy, rising economies possibly create innovations and hence more opportunities for litigation, and bankruptcy litigation is more common when the economy slows down (Clemenz and Gugler 2000). Empirical evidence also indicates that economic performance and employment lawsuits are negatively related (Siegelman and Donohue III 1995). Fourth, in general, parties living in more prosperous regions can be presumed to have a higher ability to pay potential litigation costs (Sobbrio, D'Agostino and Sironi 2010), which impacts the demand of any type of civil litigation. Since GDP is expected to impact most types of civil cases, we include it as a control. This coincides with other studies that use civil litigation as a dependent variable (Carmignani and Giacomelli 2010, Buonanno and Galizzi 2014, Clemenz and Gugler 2000). Given that the impact of GDP could be positive or negative, we have no prior expectations as regards the sign of the economy's effect on litigation, other things equal.

Finally, we include four region-specific (linear) time trends to capture regional differences (WEST, EAST, NORTH, and SOUTH). ${ }^{7}$

Table 1 provides basic descriptive statistics for the dependent and independent variables included in our analysis, along with their respective definitions. The statistics show that litigation rates are strikingly disparate across the countries in our sample. Specifically, looking at the interquartile range $\left(q_{0.75}-q_{0.25}\right)$, we see that the number of incoming cases per 10,000 inhabitants in higher-litigation countries (upper bound of IQR) exceeds the number in lower-litigation countries (lower bound of IQR) by a factor 2.9, yet ranging from 18 cases in Finland to 955 cases in Russia, and an average of 240. The average of pending caseloads is equal to 102 cases per judge, with a minimum of six cases in Turkey and a maximum of 644 cases in Italy. A judge on average solves 132 court cases, where resolved cases range between 10 cases in Finland and 441 cases in Italy. Also, judicial independence varies considerably across countries, where the average score (on the 1-7 scale) is 4.09, with a minimum value of 2 in Ukraine and a maximum value of 6.63 in Finland.

$<$ Table 1 about here>

Figure 1 illustrates the positive correlation between country-level litigation rates and pending cases. The correlation coefficient is $\mathbf{0 . 3 3 6}$, and is statistically significant at the 5 percent level. Evidently, a positive correlation is not in accordance with the congestion-equilibrium hypothesis. However, it is premature to draw any inferences on the basis of this correlation; i.e., for making causal inferences, we should rely on econometric techniques.

<Figure 1 about here>

\subsection{Empirical Model Specification}

To estimate the relationship between court backlogs and litigation rates across national jurisdictions, we develop a simple empirical model of the following form:

$$
L I T_{\mathrm{it}}=\beta_{0}+\beta_{1} P E N_{\mathrm{it}}+\beta_{2} R E S_{\mathrm{it}}+\beta_{12}\left(P E N_{\mathrm{it}} \times R E S_{\mathrm{it}}\right)+\beta_{3} I N D_{\mathrm{it}}+\beta_{13}\left(P E N_{\mathrm{it}} \times I N D_{\mathrm{it}}\right)+\gamma^{\prime} \text { Controls }_{\mathrm{it}}+\lambda_{\mathrm{r}} t+\mathrm{c}_{\mathrm{i}}+\varepsilon_{\mathrm{it}}
$$

\footnotetext{
${ }^{6}$ Our dependent variable includes litigious civil and commercial cases (such as divorce, contract, employment and insolvency cases). Administrative law cases (i.e. disputes between citizens and authorities) are not included.

${ }^{7}$ The inclusion of time dummies was ultimately abandoned as they were found (on the basis of unreported results) to be statistically insignificant in all instances.
} 
where $L I T$ is the litigation rate observed in country $i$ in year $t, P E N$ is the average number of pending cases per judge (a proxy for court backlogs), RES is the average number of resolved cases per judge (a proxy for court productivity), and IND is the degree of independence of a country's judicial system. We added GDP per capita and its square as control variables, following Jacobi (2009), while $\lambda_{r} t$ represent region-specific linear time trends. Finally, $c_{i}$ are unobserved country-specific effects of time-invariant variables (with zero mean), and $\varepsilon_{\text {it }}$ represents the idiosyncratic error term which is assumed to be i.i.d. ${ }^{8}$

An important feature of our empirical model in Equation (2) is the inclusion of two multiplicative interaction terms ${ }^{9}$, to capture the idea that the role of PEN in affecting $L I T$ is likely to be moderated by other covariates. The first interaction term is $P E N \times R E S$, which is included to allow the effect of $P E N$ to depend on the number of resolved cases per judge, where the latter is used as a proxy for court productivity (Dakolias 2014). The second interaction term is $P E N \times I N D$, which is incorporated to account for the institutional context prevailing in a country, of which the degree of independence of the judicial system is clearly an important constituent factor since justice must be rooted in confidence (Hanssen 1999).

Taking into account the interactions, the effect of PEN on LIT can be expressed as

$$
\eta=\frac{\Delta E[L I T \mid X]}{\Delta P E N}=\beta_{1}+\beta_{12} R E S+\beta_{13} I N D
$$

where the effect of PEN on LIT is contingent on given ("interesting") values of RES and IND, respectively. Evidence in support of the congestion-equilibrium hypothesis would imply an inverse relationship between $P E N$ and LIT; that is, $\hat{\eta}<0$ (see also Priest 1989, p. 543). Note, however, that an inverse relationship does not necessarily require $\hat{\beta}_{1}$ to be negative, and that the sign of $\hat{\eta}$ also depends on the signs of $\widehat{\beta}_{12}$ and $\widehat{\beta}_{13}$ as well as on the values of RES and/or IND. ${ }^{10}$

To form confidence intervals or test hypotheses about the effect of PEN on LIT, as specified in Equation (3), the required standard errors are computed from

$$
\begin{aligned}
\operatorname{Var}(\hat{\eta})=\operatorname{Var}\left(\frac{\Delta \mathrm{E} \overline{[L I T \mid} X]}{\Delta P E N}\right)=\operatorname{Var}\left(\widehat{\beta}_{1}\right)+\operatorname{Var}\left(\widehat{\beta}_{12}\right) R E S^{2}+\operatorname{Var}\left(\widehat{\beta}_{13}\right) / N D^{2} \\
+2 \operatorname{Cov}\left(\widehat{\beta}_{1}, \widehat{\beta}_{12}\right) R E S+2 \operatorname{Cov}\left(\widehat{\beta}_{1}, \widehat{\beta}_{13}\right) I N D+2 \operatorname{Cov}\left(\widehat{\beta}_{12}, \widehat{\beta}_{13}\right)(R E S \times I N D)
\end{aligned}
$$

The inclusion of PEN (our main variable of interest) in combination with RES is primarily intended to account for the time (waiting) factor when explaining LIT. While the number of pending cases per judge provides a measure of the (historical) backlog of court cases, the number of resolved cases per judge in a given year proxies the productivity of judges. At first sight, one would expect that the latter has already been captured by pending cases. However, backlogs are often a result

\footnotetext{
8 We specify the empirical model in terms of the original scale of the variables rather than using their logs (and estimating elasticities or semi-elasticities). This choice is motivated as follows. First, there is no substantive or theoretical reason for using log-transformed variables. Second, the dependent variable LIT and the key independent variables PEN and RES are defined as rates, in which case it is more natural to think in terms of absolute changes (or changes in numbers) rather than in terms of percentage changes in rates. Third, the variable IND is measured on a 7-points Likert scale, in which case taking a log is in fact meaningless. Finally, the log-transformation of LIT would turn its (initially) positively skewed distribution into a negatively skewed one, so the transformation even fails to make the distribution normal.

${ }^{9}$ We specify the empirical model in terms of the original scale of the variables rather than using their logs (and estimating elasticities or semi-elasticities). This choice is motivated as follows. First, there is no substantive or theoretical reason for using log-transformed variables. Second, the dependent variable LIT and the key independent variables PEN and RES are defined as rates, in which case it is more natural to think in terms of absolute changes (or changes in numbers) rather than in terms of percentage changes in rates. Third, the variable IND is measured on a seven-points Likert scale, in which case taking a log is, in fact, meaningless. Finally, the log-transformation of LIT would turn its (initially) positively skewed distribution into a negatively skewed one, so the transformation even fails to make the distribution "normal".

${ }^{10}$ It should be noted that the sign of $\beta_{1}$ (coefficient on the main term) is uncertain a priori. Moreover, its magnitude has no substantive meaning on its own, unless RES and IND are both equal to zero-a situation which is ruled out in reality. Some researchers would suggest that the interaction terms undermine the interpretation of the regression coefficient associated with the main term (PEN in our case). The point, however, is that researchers sometimes fail to notice the change in the interpretation of the coefficient estimate for the main term when the interaction term is added.
} 
of low court productivity in the past. Accordingly, we distinguish between the current productivity of judges (providing information on the resolution of cases in the current period) and the historical productivity - giving rise to more pending cases in the current period.

The reason why we interact PEN with IND is because the time effect, expounded by Priest (1989) in explaining the congestion equilibrium, assumes a "properly functioning" judiciary. From a theoretical point of view, we expect a judiciary to be independent. Nevertheless, a lack of independence is an enduring concern in many European judiciaries (Grajzl, Dimitrova-Grajzl and Zajc 2016). Therefore, an important advantage of our model is that it allows us to test whether the anticipated time effect that discourages litigation is contingent upon the extent to which a country's judiciary is independent.

\section{Estimation Method: Unconditional Quantile Regression}

\subsection{Moving Beyond Mean Regression}

Most applied econometric research in law and economics has focused on how changes in an explanatory variable affect the mean of an outcome variable. Due to its singular focus on the mean (only one estimate across the entire distribution of the dependent variable), this approach masks the fact that the distribution of the outcome variable can change in ways not revealed by an examination of averages. For example, both researchers and policymakers might be interested in knowing what happens to the entire distribution of the dependent variable, to the "winners" and the "losers" in the population under study, in addition to the mere averages.

To overcome the limitations of conventional mean regressions and improve our understanding of the relationship between court backlogs and litigation rates across countries, we rely on quantile regression (QR). In sharp contrast with earlier applied research using QR, we do not apply the conditional quantile regression (CQR), developed by Koenker and Bassett (1978). ${ }^{11}$ The reason is simply that we are not interested in the quantiles of the distribution defined conditional on the values taken by all other covariates ("within-group" heterogeneity). Our main interest lies with estimating the (average) effects of court backlogs at different quantiles of the unconditional-or marginal-distribution of litigation rates across national jurisdictions. Therefore, we use the unconditional quantile regression (UQR) method, recently introduced by Firpo, Fortin, and Lemieux (2009). ${ }^{12}$ UQR allows us, for example, to contrast the effects of PEN on LIT in lightly litigious versus heavily litigious countries.

\subsection{Re-Centered Influence Function and RIF-OLS Regression}

The UQR estimator builds upon the concept of re-centered influence function (RIF). In practice, the RIF is established as a particular transformation of the dependent variable $Y$ for different quantiles of its unconditional distribution.

Following Firpo, Fortin, and Lemieux (2009), the RIF of the $\tau$-th quantile of the $Y$ distribution is defined as

$$
\operatorname{RIF}\left(Y ; q_{\tau}\right)=q_{\tau}+\frac{\tau-1\left\{Y \leq q_{\tau}\right\}}{f_{Y}\left(q_{\tau}\right)}
$$

where a feasible RIF can be computed on the basis of the sample data by estimating the sample quantile $\mathrm{q}_{\tau}$, estimating the density $f_{Y}\left(q_{\tau}\right)$ at the point $q_{\tau}$ using a (Gaussian) kernel method, and forming an indicator function $I\left\{Y \leq q_{\tau}\right\}$, which indicates whether the value of the outcome variable $Y$ is below $q_{\tau}$. For example, for the 10 th percentile of the distribution, the feasible empirical RIF would be computed as

\footnotetext{
${ }^{11}$ Some prominent examples in the context of courts and legal studies are Britt (2009), Cross and Donelson (2010) and Nowacki (2015). However, the use of CQR might not have been appropriate to provide answers to the research questions posed by these authors.

${ }^{12}$ We just give a brief account of UQR here. For more details, see the original paper by FFL (2009). Some good and accessible expositions can be found in Fournier and Koske (2012), Killewald and Bearak (2014), and Porter (2015). These articles also clearly explain the differences between CQR and UQR as well as the proper interpretations of the estimates in both instances.
} 


$$
\widehat{\operatorname{RTF}}\left(Y ; \hat{\mathrm{q}}_{0.10}\right)=\widehat{\mathrm{q}}_{0.10}+\frac{0.10-1\left\{Y \leq \hat{\mathrm{q}}_{0.10}\right\}}{\hat{\mathrm{f}}_{Y}\left(\hat{\mathrm{q}}_{0.10}\right)}
$$

An interesting feature of the RIF of the dependent variable $Y$ is that its expectation (or mean) is equal to the specified quantile,

$$
\operatorname{E}\left[\operatorname{RIF}\left(Y ; q_{\tau}\right)\right]=q_{\tau} .
$$

FFL (2009) have further shown that if the RIF of $Y$ is conditioned on a set of covariates $X$, it follows that

$$
E_{X}\left\{E\left[R I F\left(Y ; q_{\tau}\right) \mid X\right]\right\}=q_{\tau} \text {. }
$$

If we next model the conditional expectation of $\operatorname{RIF}\left(Y ; q_{\tau}\right)$ as a function of covariates $X$, we obtain the unconditional quantile regression (UQR) model, given by

$$
\operatorname{E}\left[\operatorname{RIF}\left(Y ; q_{\tau}\right) \mid X\right]=X^{\prime} \beta_{\tau^{\prime}}
$$

where $\beta_{\tau}$ measures the change in the $\tau$-th quantile of the unconditional distribution of $Y$ resulting from a marginal change in the variable of interest, $X_{1}$ in $X$, holding all the other covariates, $X_{2}$ in $X$, constant. The estimation of the UQR model can be implemented as a conventional OLS regression; it is called the RIF-OLS regression, where the dependent variable $Y$ is simply replaced by the $\operatorname{RIF}\left(Y ; q_{\tau}\right)$ for each quantile of interest.

The RIF transformation in Equation (5) has the useful characteristic that UQR combines the attractive features of both OLS and quantile regression. That is, UQR allows the marginal effects to be estimated at different points of the distribution, which is the "quantile part". What this means, in plain speaking, is that the expected value of $Y$ at each quantile of the (unconditional) distribution of LIT can be estimated, hence allowing us to go beyond the singular focus on the mean of the distribution. In other words, UQR has the quality of respecting the Law of Iterated Expectation, which is the "OLS part". ${ }^{13}$ The latter allows UQR to provide estimates of the effect of a covariate $X$ at each point of the distribution of the outcome variable $Y$ while keeping everything else constant. Therefore, unlike the estimates obtained using CQR, the estimates returned by UQR have a direct interpretation, much the same as the estimates resulting from conventional OLS, through its focus on the entire population, rather than on some sub-population defined conditional on specific values taken by the covariates.

\subsection{Random Effects in UQR}

In our application below, we use the random effects (RE) estimator in UQR. That is, we exploit the within and between dimensions of the data, so combining the variation over time and across countries, respectively. The main reason for choosing the RE rather than the fixed effects (FE) estimator is that certain covariates do not vary much over time, which makes it hard to obtain reliable estimates of their effects, apart from the fact that we have only a short panel $(T=4)$. This can be seen from the between and within statistics reported in Table 1. Specifically, the within (time-series) variations of our key independent variables are rather small compared to their between (cross-sectional) variations: the (percentage) ratios of the within-to-between variances are $12.9 \%$ for PEN $\left(=100 \times 42.6^{2} / 118.8^{2}\right), 13.6 \%$ for $R E S\left(=100 \times 31.0^{2} / 84.1^{2}\right)$, and only $4.8 \%$ for IND $\left(=100 \times 0.296^{2} / 1.353^{2}\right)$ (see Table 1$)$.

\footnotetext{
${ }^{13}$ The OLS counterpart of this property is the known result that $E_{X}[E(Y \mid X)]=E(Y)$, which implies that the conditional and unconditional values of $Y$ have equal expectations.
} 
To implement the proposed UQR-RE approach, we follow the two-step procedure suggested by Borgen (2016). In the first step, we obtain the RIFs (see Equation (5)) for selected quantiles of the litigation-rate distribution across countries. In the second step, we use the RE estimator with the RIFs as the dependent variable.

\section{Empirical Results}

This section discusses the results obtained using three different estimators, summarized in Table 2. The first is the pooled OLS (POLS) estimator; the second is the conventional random effects (RE) estimator; and the third is the (new) random effects in unconditional quantile regression (UQR-RE) estimator. All three estimators use both between (cross-section) and within (time-series) variation in the data to identify the effect of PEN on LIT. Our primary focus is on the results obtained using UQR-RE, while those returned by POLS and RE are presented only for the sake of comparison. ${ }^{14}$

$<$ Table 2 about here>

The estimation results for the model in Equation (2) are summarized in Table 2 for POLS (column 1), RE (column 2), and UQR-RE (columns 3-9) evaluated at selected percentiles of the litigation-rate distributions. ${ }^{15}$ In panel A of Table 2, we present the estimated coefficients $\left(\beta_{\tau}\right)$, whereas in panel $B$, we look at the (partial) effects of pending cases, $P E N$, on litigation, LIT, evaluated at different values for the interacting variables (effect modifiers) RES and IND $\left(\eta_{\tau}\right)$-according to Equation (3).

\subsection{Results for POLS and RE}

We start by looking at some benchmark results showing the average parameter estimates obtained using POLS and RE, 16 which are reported in columns 1 and 2 of Table 2 , respectively.

We see in panel B of Table 2 that both POLS and RE return a negative and significant effect of PEN on the mean of the crosscountry LIT distribution, which implies a parallel "location shift" of the distribution to the left-insofar as the countries have a high degree of IND. For example, at high levels of RES and IND, the RE estimate $(-0.732)$ is only about $66 \%$ of the POLS estimate (-1.111). At low degrees of IND, though, the average effect of $P E N$ turns out to be mostly insignificant.

Although these results are clearly in accordance with the predictions of the congestion-equilibrium hypothesis, they are rather uninformative; due to their singular focus on the mean, these results do not tell us anything about the effect of $P E N$ at other points of the LIT distribution-at, say, the lower end of the LIT distribution (low-litigation countries) as compared to the those at the upper end of the distribution (high-litigation countries). Finding an inverse relationship on average between PEN and LIT does not necessarily mean that the congestion equilibrium occurs in every country of our sample population (besides, the "average country" does not exist). To get a more informative picture, we now move on to the results returned by our UQR-RE estimations.

\subsection{Results for UQR-RE}

From an applied researcher's perspective, we are much more interested to see how the effect of PEN varies at different quantiles of the LIT distribution, particularly with reference to the potential policy implications. Therefore, we now turn to the quantile estimates obtained using UQR-RE, which are at the heart of the present paper.

\footnotetext{
${ }^{14}$ We do not report results generated by CQR for the sake of comparison with those obtained using UQR, for the simple reason that UQR and CQR estimate different objects that are not directly comparable. Apart from that, CQR estimates are also more difficult to interpret.

${ }_{15}^{15}$ POLS and RE estimations were implemented using Stata's commands regress and xtreg, respectively. UQR-RE was implemented using $x$ treg in the second step, after generating the RIF's of the dependent variable for selected quantiles in the first step using the built-in rifreg command, which is available at http://faculty.arts.ubc.ca/nfortin/datahead.html. It should be noted that the RIF's are derived on the basis of the estimation sample.

${ }^{16}$ It is interesting to note that the Hausman test did not show any preference for the fixed-effects (FE) estimator over the random-effects (RE) estimator. That is, the test of the null hypothesis of no systematic differences between FE and RE estimates could not be rejected (with chi2 $=5.94$, and $p$-value $=0.746$ ).
} 
Within the UQR framework, Equation (3) has to be adjusted such that the effect of PEN on LIT is calculated for selected quantiles of the LIT distribution. Specifically, for the t-th quantile of the LIT distribution, we have

$$
\eta_{\tau}=\frac{\Delta_{\tau} E\left[R I F\left(L I T ; q_{\tau}\right) \mid X\right]}{\Delta P E N}=\beta_{1, \tau}+\beta_{12, \tau} R E S+\beta_{13, \tau} I N D
$$

A significant finding from the UQR-RE results is that the responsiveness of LIT to changes in PEN is not uniform across the quantiles of the unconditional LIT distribution. Two important observations stand out. First, the negative effect of PEN on $L I T$ is more pronounced in heavily litigious countries, as compared to low-litigation countries. Such heterogeneity along the litigation-rate distribution would have remained unknown if we had only used conventional mean regressions. Second, the negative effect of $P E N$ becomes stronger with an increasingly independent judicial system. Thus, litigation rates fall in response to an increase in pending cases only in high-litigation countries where judicial independence is high.

A possible explanation of why the negative effect of PEN on LIT is more pronounced in heavily litigious countries, is that potential plaintiffs are more inclined to take a similar dispute to court compared to plaintiffs in low-litigation countries (this might be, for example, a consequence of legal culture). Therefore, disputes with relatively small claims are litigated as well. When backlogs increase, many of these marginally viable cases result in a lower expected utility of filing a lawsuit, and settlement becomes more interesting. In countries with low litigation rates, however, only disputes of considerable importance result in expected utilities sufficiently high to file suit in the first place. Therefore, increased backlogs will deteriorate the expected court award $a$, but the resulted decrease in expected utility will probably not suffice to make settlement more attractive. Therefore, litigation rates in low litigious countries are less likely to be impacted by court backlogs.

A possible reason why we only find a negative and statistically significant effect for countries with high levels of judicial independence, is that plaintiffs have very high winning probabilities in countries where judges are susceptible to influences (such as bribes or political preferences). In other words, given that plaintiffs have a high certainty of winning the case, they are willing to wait longer for the favorable verdict. That is, the depreciation of $a$ as a consequence of backlogs (which results in a higher $t$ ), will be offset by the increase in $\mathrm{dF}(\mathrm{a})$ as a consequence of the increased winning probability. In countries with high levels of judicial independence, on the other hand, judges are independent and therefore the verdict might be less predictable (for example, the judge does not systematically favor a certain type of plaintiff). Consequently, potential plaintiffs in these countries will be deterred by backlogs to a larger extent and settlements therefore become a more appealing alternative to resolve the case.

To ease the assessment of our results, Figure 2 graphically visualizes the estimated UQR-RE coefficients as quantile (Q) plots, for 19 quantiles (from the 5th to the 95th percentile) of the LIT distribution. Panel A shows the effects for low levels of RES, while panel B displays those for high levels of RES. Under low IND, the impact of PEN tends to oscillate around zero, regardless of the level of RES. Conversely, under high IND, the quantile plot is monotonically decreasing as we move up across the distribution from about the 50th quantile onwards. In fact, the effect of PEN turns out to be slightly positive around the median, but then becomes increasingly negative and significant as we move to the upper end of the distribution. This Q-plot pattern clearly suggests that the strongest negative impacts of PEN on LIT seem to emerge primarily in heavilylitigious countries experiencing high levels of judicial independence. Importantly, the negative impact of PEN, for countries with highly independent judiciaries, is in accordance with our prior expectations that backlogs tend to lower the propensity to litigate.

The (relatively small) positive impact of PEN on LIT in the middle range of the LIT distribution is somewhat puzzling. Clearly, it is unwieldy to comment on all the estimates at each individual quantile of the LIT distribution. Even though the effect of PEN is basically oscillating around zero, the apparent anomalies (counter-intuitive evidence at some quantiles) offer a constructive area for future research. As we will explain in section 5.4., these estimates are possibly positively biased because of endogeneity.

<Figure 2 about here> 
We also examined the heterogeneity of the impact of PEN on LIT defined over three segments of the LIT distribution, and under different levels of RES and IND. The "low-end heterogeneity" is measured as $\hat{n}_{0.50}-\hat{n}_{0.10}$; "high-end heterogeneity" as $\hat{n}_{0.90}-\hat{\eta}_{0.50}$, and "overall heterogeneity" as $\hat{\eta}_{0.90}-\hat{n}_{0.10}$. We use a Wald-type test to test the null hypothesis of pair-wise equality of the unknown impacts $\eta_{\tau}$ (implying homogeneity). The test results have been summarized in Table 3.

It is interesting to see that, irrespective of the level of RES but conditional on high IND, the low-end heterogeneity is statistically insignificant. That is, the effects of PEN on LIT remain essentially constant (and largely insignificant), whereas the high-end heterogeneity is strongly significant. The impact of PEN on LIT thus becomes considerably more significant as we move up along the LIT distribution. Overall, the test results clearly illustrate the usefulness of using the UQR approach by showing that the extent to which country-level litigation rates respond to pending cases depends on a given country's position in the distribution of the countries' levels of litigiousness.

$<$ Table 3 about here>

The same pattern emerges in Figure 3. The graphs show estimated kernel-density functions to illustrate what happens to the shape of the LIT distribution following a one-half standard deviation increase in PEN (which amounts to 64 more cases per judge annually) under a high degree of judicial independence, holding other things constant. Specifically, it can be seen that the distribution is somehow "sandwiched", where mainly the upper part of the distribution has been strongly pushed to the left. Therefore, the litigiousness in high-litigation countries is affected most by an increase in pending cases. The abovementioned push to the left is a bit less pronounced when the number of resolved cases in a country is low.

$<$ Figure 3 about here $>$

Based on the RE results in panel B, column 2 of Table 2, an increase in court backlogs equivalent to one-half standard deviation of the PEN variable (which amounts to about 64 more pending cases per judge annually) ${ }^{17}$ in countries with high levels of judicial independence is associated with an average reduction of a country's rate of litigation by $12.2 \%$ (or 29 cases per 10,000 inhabitants) to $19.5 \%$ (or 47 cases per 10,000 inhabitants), for low and high numbers of resolved cases respectively. ${ }^{18}$ However, based on the UQR-RE results in panel B, column 9 of Table 2, we find that in heavily litigious countries, the same increase in court backlogs is expected to reduce those countries' litigation rates by $36.1 \%$ and $36.2 \%$ (or about 158 cases per 10,000 inhabitants in both instances), for high and low resolution rates, respectively. ${ }^{19}$ In addition, from the estimated kernel density functions for the actual and simulated LIT distributions, we also find that the dispersion (standard deviation) of the LIT distribution decreases by about 49\%, regardless of the level of RES. In other words, the disparity across countries in terms of litigation would be appreciably reduced. ${ }^{20}$

Interestingly, we find that GDP per capita has a negative but insignificant effect on litigation in the lower part of the LIT distribution, whereas the effect is found to be positive but insignificant for most of the upper part of the distribution. Only from the 85th percentile onwards, thus for the highest-litigation countries, we find a positive and significant effect of GDP per capita. These findings may also explain why earlier work on litigation has so frequently reported mixed results.

\subsection{Robustness Checks: Results for Correlated RE in UQR}

\subsubsection{Correlated Random-Effects Model}

As a first robustness check, we estimated a correlated RE (CRE) model (see Wooldridge 2013, p. 479), as an alternative to the fixed effects (FE) approach. The CRE model is specified as follows:

$$
L I T_{\text {it }}=\beta_{0}+\beta_{1} P E N_{i t}+\beta_{2} R E S_{i t}+\beta_{12}\left(P E N_{i t} \times R E S_{i t}\right)+\beta_{3} I N D_{i t}+\beta_{13}\left(P E N_{i t} \times I N D_{i t}\right)+\gamma_{1} G D P P C+\gamma_{2} G D P P C^{2}+
$$

\footnotetext{
${ }^{17}$ To get a sense of the size of this change, recall that the mean in the estimation sample is 102 cases per 10,000 residents (see Table 1). ${ }^{18}$ The percentage reductions in LIT of $12.2 \%$ and $19.5 \%$ are calculated as $100 \times(-0.457 \times 64.2) / 240.4$ and $100 \times(-0.732 \times 64.2) / 240.4$ for low and high levels of RES, respectively (see estimated effects for RE reported in panel B, column 2 of Table 2 ).

${ }^{19}$ The percentage reductions in LIT of $36.2 \%$ and $36.1 \%$ are calculated as $100 \times(-2.461 \times 64.2) / 436.9$ and $100 \times(-2.458 \times 64.2) / 436.9$ for high and low levels of RES, respectively (see estimated effects for UQR-RE reported in panel B, column 9 of Table 2).

${ }^{20}$ The simulation results are presented here for illustrative purposes only, where it should be taken into account that the RIF regression is a linear approximation that is only valid for "marginal" changes in an independent variable.
} 


$$
\vartheta_{1} \overline{P E}_{i}+\vartheta_{2} \overline{R E S}_{i}+\vartheta_{3} \overline{I N D}_{i}+\vartheta_{4} \overline{G D P P C_{i}}+\vartheta_{5} \overline{G D P P C}_{i}^{2}+\Sigma_{r=6}^{9} \vartheta_{r} \bar{t}_{r-5}+r_{i}+\varepsilon_{i t}
$$

where the added time-averages control for the correlation between the country-specific effects and the independent variables (for $t=1, \ldots, 4$ ), and the unobservable $r_{i}$ is uncorrelated with the independent variables. The time averages of the regional trends $\bar{t}_{r}$ are also included given the unbalanced nature of our panel (i.e., averages may differ across regions, depending on how many years we have for each country $i$ in region $r){ }^{21}$

An attractive feature of the CRE model in Equation (10) is that it controls for the systematic (fixed) "historical" differences across countries in the levels of the independent variables, which may also explain differences in litigation rates. For example, by entering the time average of IND, the CRE model allows for the inclusion of systematic differences in litigation rates between, say, historically high-IND and low-IND countries. ${ }^{22}$

The results for POLS1 (POLS with time averages included) and standard CRE are presented in columns 1 and 2 of Table 4, respectively, while the estimates for CRE in UQR (UQR-CRE) are summarized in columns 3-9. The structure of this table is largely the same as that of Table 2, though to save space we only present the effects of PEN on LIT for selected levels of RES and IND.

$$
<\text { Table } 4 \text { about here> }
$$

When looking at the results obtained for UQR-CRE, we see that the pattern displayed by their UQR-RE counterparts in Table 2 remains broadly intact, though less pronounced, as also shown in Figure 4. This finding is likely to be atributable to multicollinearity, which emerges from the fact that the key independent variables show little within variation, hence giving rise to high correlations with their respective time averages. ${ }^{23}$

$<$ Figure 4 about here>

Importantly, however, $F$ tests of the joint significance of the coefficients on the time averages $\left(H_{0}: \vartheta_{1}=\vartheta_{2}=\ldots=\vartheta_{9}=0\right)$ tell us that the validity of the RE cannot be rejected in the upper half of the LIT distribution (say, upwards from about the 40th percentile). ${ }^{24}$ These results are reassuring, as they lend support to the UQR-RE results reported in Table 2, particularly the estimates pertaining to the upper half of the distribution where the most important effects of PEN on LIT take place under high IND.

\subsubsection{Linear Dynamic Panel Data Model}

As a further robustness check, e also estimated a linear dynamic panel-data model, by applying the Arellano and Bover (1995) system GMM estimator, to see whether concerns about dynamic misspecification of the mean regression are warranted. An additional aspect of the $A B$ estimation is that potential endogeneity issues can be addressed by using "internal" instrument - that is, by using instruments based on lagged values of the model variables. Unfortunately, though, it is not possible to estimate a dynamic panel-data model within the UQR framework, given that lagged values of the RIFtransformed dependent variable would have to be entered as additional regressors. Finally, the AB estimation allows us to estimate both "short-run" and "long-run" effects of PEN on the mean of the LIT distribution.

The long-run effects of PEN on LIT can be calculated $a s^{25}$ :

\footnotetext{
${ }^{21}$ The time averages of the interaction terms have not been included, however, due to problems of collinearity.

${ }^{22}$ The exclusion of the time averages of the interaction terms implies, however, that the we are not able to reach "full" equivalence between the CRE and FE estimates from the model in Equation (10).

${ }^{23}$ The correlations between the key independent variables (PEN, RES, and IND) and their respective time averages oscillate around a value as high as 0.95; the correlation between GDPPC and its time average is 0.76 . Due to the fact that the within variation (variation over time) in the covariates is small relative to the between variation (variation across countries), FE estimates lack reliability. For this reason, the adoption of the FE approach has not been pursued in the present paper.

${ }^{24}$ Only in those instances where $H_{0}$ is rejected at a sufficiently small significance level, we should reject RE/UQR-RE in favor of FE/UQR-FE. Though, the estimated effects of interest are insignificant anyway across the lower half of the LIT distribution.

${ }^{25}$ Actually, we could say that, given the short time-span of the panel (seven years only), we should perhaps interpret the "long-run" effects, calculated on the basis of Equation (11) below, as medium-term effects rather than truly long-run effects.
} 


$$
\eta^{\mathrm{LR}}=\frac{\Delta \mathrm{E}[L I T \mid X]}{\Delta P E N}=\frac{\beta_{1}+\beta_{12} R E S+\beta_{13} I N D}{1-\alpha}
$$

where $\alpha$ is the coefficient on the lagged dependent variable, $L I T(t-1)$.

The results of the $A B$ estimations are shown in Table 5.

$$
<\text { Table } 5 \text { about here> }
$$

Three conclusions can be drawn from the results obtained using a dynamic panel data model. First, the patterns show that the effects of PEN on LIT are broadly in line with those of POLS and RE, being zero or slightly positive for low IND and strongly negative for high IND - although the AB estimates are a somewhat more pronounced, as far as the effects on the mean of the LIT distribution is concerned. Second, even though potential misspecification errors due to the omission of dynamic factors may raise some concerns, in the present application the difference between long-run and short-run effects are not statistically significant. Third, the AB estimates are not in disagreement with the baseline UQR results reported in Table 2. The principal gain of using UQR is that it shows that the negative effects are likely to occur primarily in the upper end of the LIT distribution conditional upon a high level of IND.

\subsection{Endogeneity Issues}

A legitimate concern may arise about the directionality of causation. More precisely, the number of pending cases in a country may be endogenous due to reverse causation, so that higher litigation may be a cause rather than a consequence of pending cases. If this is the case, it is not generally possible to disentangle correlation from causation. Earlier we noted that litigation rates across countries are positively correlated with pending cases (correlation $=0.344, p$-value $<0.05$ ). However, the fact that we find a strong negative relationship between of PEN and LIT (at least for high-litigation jurisdictions with a high degree of judicial independence) shows that the reported estimations have already gone a long way in mitigating the impact of endogeneity of PEN due to reverse causality.

Despite the difficulties that may exist in making causal inferences (which are not unique to our study), the present analysis provides nevertheless a rich picture of the heterogeneous relationship between pending cases and litigation, which would have remained concealed if we had used simple mean regressions. That is, even though pending cases may suffer from endogeneity, we have disclosed distributional changes that may take place in the judicial landscape by moving beyond the rather uninformative "averages". Moreover, the strong and robust empirical regularities we have found are largely in accordance with theoretical predictions of the existence of a congestion equilibrium.

A standard remedy for the endogeneity problem would be to use an instrumental variable (IV) for PEN (Wooldridge 2013). Yet, we have not conducted an IV strategy for several reasons. First, there is not yet an established method to incorporate IVs into a RIF regression. That is, UQR always assumes the presence of exogenous covariates, where potential biases may, however, be rather small (Firpo, Fortin and Lemieux 2009, p. 955).

Second, other recent methods aimed at "marginalizing" the quantile effects that allow for instrumentation (e.g., Powell 2012) are still at their infancy, having rather limited implementation capabilities.

Third, even if IV were possible, in a pure methodological sense, it is always difficult-if not impossible-to find suitable instruments that are correlated with PEN (relevant) but not with LIT (exogenous). In this context, one should recall the known result that using questionable instruments may do more harm than good, hence leaving the results reported in this paper to be currently the best possible approximation (Bound, Jaeger and Baker 1993). ${ }^{26}$

Fourth, it is not clear a priori that endogeneity concerns affecting the estimated mean of the outcome also translate into the estimated quantiles of a distribution. If the endogeneity biases the whole distribution up or down, this clearly affects

\footnotetext{
${ }^{26}$ Moreover, IV estimators are innately biased, performance in small sample may be poor, and in the presence of weak instruments the loss of precision is often severe, so that IV estimation is not really worth pursuing.
} 
the estimated mean but not necessarily the estimates of the distributional impacts (such as those reported in Table 2), which depend on the distances between the quantiles but not on their levels. ${ }^{27}$ In short, a comparison of the effects of PEN on LIT for low- versus high-litigation countries would still be valid and substantively meaningful, provided that the potential endogeneity biases remain the same across the entire distribution (see also, e.g. Fournier and Koske 2012).

Finally, and most importantly, if reverse causation would be truly a problem, the estimated effects of PEN on LIT reported in Table 2 are likely to be positively biased, hence understating PEN's negative-and overstating its positive-relationship with LIT. In other words, our estimated effects in Table 2 can be viewed as upper bounds. ${ }^{28}$

\section{Conclusion}

The congestion equilibrium theory, introduced by Priest (1989), states that efforts to reduce court delay are likely to be offset by an increased tendency to litigate by parties. The underlying assumption is that rational parties account for court backlogs (i.e., waiting time) in their decision to litigate and hence an increase in the backlogs is expected to reduce litigation rates. This paper is the first to empirically investigate the congestion equilibrium hypothesis by exploiting a biennial panel dataset for 36 European countries over the period 2006-2012. Specifically, we examine the impact of court backlogs on litigation rates for different degrees of a country's litigiousness.

For our analysis, we apply the new estimation method of unconditional quantile regression (UQR). This method allows us to assess the impact of pending cases on a country's litigation rate using data from a population of heterogeneous countries in terms of litigation behavior (dependent variable, LIT) and court backlogs (key determinant, PEN), as well as in terms of important contextual variables such as case resolution (RES) and judicial independence (IND). The UQR method gives a more complete picture of the relationship between backlogs and litigation than conventional mean regressions.

Our results show that the congestion equilibrium hypothesis holds for highly litigious countries with a moderate or high judicial independence. For those countries, our results provide compelling evidence of the existence of an inverse relationship between litigation rates and court backlogs. This suggests that a reduction in court congestion induces additional disputants to go to court. As a result, extra "judge time" is likely to be (at least partly) ineffective in reducing court delay, since it creates additional demand (showing an increase of up to about 50\% in heavily litigious countries). Consequently, backlog levels return to the equilibrium level again. However, we find no evidence of an inverse relationship between litigation rates and court backlogs for lightly litigious countries. Therefore, delay-reducing policies (e.g. hiring more judges) may possibly be more effective in reducing court backlogs in these countries, compared to judiciaries with high litigation rates. In short, our results indicate that a custom tailored policy approach is required to tackle the problem of court delay based on the degree of litigation and the level of judicial independence in a country.

\footnotetext{
${ }^{27}$ The distances are the same when the quantile plots in Figure 2 would shift to the left in a parallel way.

${ }^{28}$ This assertion is grounded on the following known result (e.g. Stock and Watson 2015, p. 231) that plim $\hat{\beta}=\beta+\rho_{X \varepsilon}\left(\sigma_{\varepsilon} / \sigma_{X}\right)$, where $X=$ PEN is the potentially endogenous variable, $\beta<0$ according to prior expectations, and $\rho_{x_{\varepsilon}}>0$, such that $E(\widehat{\beta})>\beta$ is a likely to be the outcome. More precisely, if some external shock causes the error term, $\varepsilon$, to change, that induces a shift in $Y=L I T$. This, in turn, may cause $X$ to rise as well. This "feedback" between $\varepsilon$ and $X$ implies that the parameter $\beta$ cannot be consistently estimated. The fact that this property applies to conventional linear regressions should not pose a problem because UQR models can be estimated using a simple OLS regression on the transformed (RIF) dependent variable.
} 


\section{References}

Arellano, Manuel and Stephen Bond. 1991. "Some Tests of Specification For Panel Data: Monte Carlo Evidence and an Application To Employment Equations." The Review of Economic Studies, 58:2, 277-297

Arellano, Manuel and Olympia Bover. 1995. "Another Look at the Instrumental Variable Estimation of Error-components Models." Journal of econometrics, 68:1, 29-51

Bachmeier, Lance, Patrick Gaughan and Norman R Swanson. 2004. "The Volume of Federal Litigation and the Macroeconomy." International Review of Law and Economics, 24:2, 191-207

Barzel, Yoram. 1974. "A Theory of Rationing by Waiting." Journal of Law and Economics, 17:1, 73-96

Bielen, Samantha, Wim Marneffe and Lode Vereeck. 2015. "Litigation decision." In Encyclopedia of Law and Economics, edited by Jürgen Backhaus, Alain Marciano and Giovanni B Ramello. New York: Springer.

Borgen, Nicolai T. 2016. "Fixed Effects in Unconditional Quantile Regression." Stata Journal, 16:2, 403-415

Bound, John, David A Jaeger and Regina Baker. 1993. The Cure Can Be Worse Than the Disease: A Cautionary Tale Regarding Instrumental Variables. NBER Technical Working Paper No. 137.

Braess, Dietrich. 1968. "Über ein Paradoxon aus der Verkehrsplanung." Unternehmensforschung 12, 258-268

Brambor, Thomas, William Roberts Clark and Matt Golder. 2005. "Understanding Interaction Models: Improving Empirical Analyses." Political analysis, 14:1, 63-82

Britt, Chester L. 2009. "Modeling the Distribution of Sentence Length Decisions under a Guidelines System: An Application of Quantile Regression Models." Journal of Quantitative Criminology, 25:4, 341-370

Buonanno, Paolo and Matteo M. Galizzi. 2014. "Advocatus, et non Latro? Testing the Excess of Litigation in the Italian Courts of Justice." Review of Law and Economics, 10:3, 285-322

Buscaglia, Edgardo and Maria Dakolias. 1999. Comparative International Study of Court Performance Indicators: A Descriptive and Analytical Account: World Bank.

Carmignani, Amanda and Silvia Giacomelli. 2010. "Too Many Lawyers?: Litigation in Italian Civil Courts." Bank of Italy Temi di Discussione (Working Paper) No. 745,

CEPEJ. 2008. European Judicial Systems. Editions 2008 (2006 Data). Efficiency and Quality of Justice. Strasbourg: Council of Europe Publishing.

CEPEJ. 2010. European Judicial Systems. Editions 2010 (2008 Data). Efficiency and Quality of Justice. Strasbourg: Council of Europe Publishing.

CEPEJ. 2012. European Judicial Systems. Editions 2012 (2010 Data). Efficiency and Quality of Justice. Strasbourg: Council of Europe Publishing.

CEPEJ. 2014. European Judicial Systems. Editions 2014 (2012 Data). Efficiency and Quality of Justice. Strasbourg Council of Europe Publishing.

Chappe, Nathalie. 2012. "Demand for Civil Trials and Court Congestion." European Journal of Law and Economics, 33:2, 343357

Christensen, Robert K. and John Szmer. 2012. "Examining the Efficiency of the U.S. Courts of Appeals: Pathologies and Prescriptions." International Review of Law and Economics, 32:1, 30-37

Clemenz, Gerhard and Klaus Gugler. 2000. "Macroeconomic Development and Civil Litigation." European Journal of Law and Economics, 9:3, 215-230

Cross, Frank B. and Dain C. Donelson. 2010. "Creating Quality Courts." Journal of Empirical Legal Studies, 7:3, 490-510

D'Agostino, Elena, Emiliano Sironi and Giuseppe Sobbrio. 2012. "Lawyers and Legal Disputes. Evidence from Italy." Applied Economics Letters, 19:14, 1349-1352

Dakolias, Maria. 2014. "Court Performance Around the World: A Comparative Perspective." Yale Human Rights and Development Journal, 2:1, 87-142

Di Vita, Giuseppe. 2010. "Production of Laws and Delays in Court Decisions." International Review of Law and Economics, 30:3, 276-281

Dimitrova-Grajzl, Valentina, Peter Grajzl, Janez Sustersic and Katarina Zajc. 2012. "Court Output, Judicial Staffing, and the Demand for Court Services: Evidence from Slovenian Courts of First Instance." International Review of Law and Economics, 32:1, 19-29

Doornik, Katherine. 2014. "A rationale for mediation and its optimal use." International Review of Law and Economics, 38:0, 1-10

Firpo, Sergio, Nicole Fortin and Thomas Lemieux. 2009. "Unconditional quantile regressions." Econometrica, 77:3, 953-973

Fournier, J. and Isabell Koske. 2012. Less Income Inequality and More Growth-Are they Compatible? Part 7. The Drivers of Labour Earnings Inequality-An Analysis Based on Conditional and Unconditional Quantile Regressions, OECD Economics Department Working Papers, No. 930, OECD Publishing.

Ginsburg, Tom; and Glenn Hoetker. 2006. "The Unreluctant Litigant? An Empirical Analysis of Japan's Turn to Litigation." The Journal of Legal Studies, 35:1, 31-59 
Grajzl, Peter, Valentina Dimitrova-Grajzl and Katarina Zajc. 2016. "Inside Post-socialist Courts: the Determinants of Adjudicatory Outcomes in Slovenian Commercial Disputes." European Journal of Law and Economics, 41:1, 85115

Gravelle, Hugh. 1990. "Rationing Trials by Waiting: Welfare Implications." International Review of Law and Economics, 10:3, 255-270

Gravelle, Hugh S.E. . 1989. "Accidents and the Allocation of Legal Costs with an Uninformed Court." The Geneva Papers on Risk and Insurance, 14:50, 11-25

Hanssen, F Andrew. 1999. "The Effect of Judicial Institutions on Uncertainty and the Rate of Litigation: The Election Versus Appointment of State Judges." The Journal of Legal Studies, 28:1, 205-232

Heaton, Paul and Eric Helland. 2011. "Judicial Expenditures and Litigation Access: Evidence from Auto Injuries." The Journal of Legal Studies, 40:2, 295-332

Ippoliti, Roberto, Alessandro Melcarne and Giovanni B Ramello. 2015a. "The Impact of Judicial Efficiency on Entrepreneurial Action: A European Perspective." Economic Notes, 44:1, 57-74

Ippoliti, Roberto, Alessandro Melcarne and Giovanni B Ramello. 2015b. "Judicial Efficiency and Entrepreneurs' Expectations on the Reliability of European Legal Systems." European Journal of Law and Economics, 40:1, 75-94

Jacobi, Tonja. 2009. "The Role of Politics and Economics in Explaining Variation in Litigation Rates in the US States." Journal of Legal Studies, 38:1, 205-233

Killewald, Alexandra and Jonathan Bearak. 2014. "Is the Motherhood Penalty Larger for Low-wage Women? A Comment on Quantile Regression." American Sociological Review, 79:2, 350-357

Kittelsen, Sverre A. C. and Finn R. Førsund. 1992. "Efficiency Analysis of Norwegian District Courts." Journal of Productivity Analysis, 3:3, 277-306

Koenker, Roger and Gilbert Bassett. 1978. "Regression Quantiles." Econometrica: journal of the Econometric Society, 46:1, 33-50

Mora-Sanguinetti, Juan S and Nuno Garoupa. 2015. "Do Lawyers Induce Litigation? Evidence From Spain, 2001-2010." International Review of Law and Economics, 44:2015, 29-41

Murrell, P. 2001. Demand and Supply in Romanian Commercial Courts: Generating Information for Institutional Reform. Maryland: IRIS Center.

Nowacki, Jeffrey S. 2015. "Race, Ethnicity, and Judicial Discretion The Influence of the United States v. Booker Decision." Crime \& Delinquency, 61:10, 1360-1385

Palumbo, Giuliana, Giulia Giupponi, Luca Nunziata and Juan Mora-Sanguinetti. 2013. Judicial performance and its determinants: a cross-country perspective. Economic Policy Paper no. 5.

Porter, S.R. 2015. "Quantile Regression: Analyzing Changes in Distributions Instead of Means." In Higher Education: Handbook of Theory and Research. Volume 30, edited by Michael B Paulsen and John C Smart. Switzerland: Springer International Publishing.

Posner, Richard A. 1997. "Explaining the Variance in the Number of Tort Suits across US States and between the United States and England." Journal of Legal Studies 26:S2, 477-489

Posner, Richard A. 2014. Economic Analysis of Law. New York: Wolters Kluwer Law and Business.

Powell, David. 2012.

Priest, George L. 1989. "Private Litigants and the Court Congestion Problem." Boston University Law Review 69:3, 527-559

Ramello, Giovanni B and Stefan Voigt. 2012. "The Economics of Efficiency and the Judicial System." International Review of Law and Economics, 32:1, 1-2

Roodman, David. 2009. "How to do Xtabond2: An Introduction to Difference and System GMM in Stata." Stata Journal, 9:1, 86-136

Rosales-López, Virginia. 2008. "Economics of Court Performance: An Empirical Analysis." European Journal of Law and Economics, 25:3, 231-251

Roussey, Ludivine and Bruno Deffains. 2012. "Trust in Judicial Institutions: An Empirical Approach." Journal of Institutional Economics, 8:03, 351-369

Siegelman, Peter and John J Donohue III. 1995. "The Selection of Employment Discrimination Disputes for Litigation: Using Business Cycle Effects to Test the Priest-Klein Hypothesis." The Journal of Legal Studies, 24:2, 427-462

Sobbrio, Giuseppe, Elena D'Agostino and Emiliano Sironi. 2010. "New Disputes and Delay in Italian Courts." Paolo Baffi Centre Research Paper, 2010-84

Stock, J.H. and M.W. Watson. 2015. Introduction to Econometrics. Essex, England: Pearson Education.

Vereeck, Lode and Manuela Mühl. 2000. "An Economic Theory of Court Delay." European Journal of Law and Economics, 10:3, 243-268

Voigt, Stefan and Nora El-Bialy. 2014. "Identifying the Determinants of Aggregate Judicial Performance: Taxpayers' Money Well Spent?" European Journal of Law and Economics, 41:2, 283-319

Wooldridge, Jeffrey M. 2013. Introductory Econometrics: A Modern Approach. Fifth edition. Mason, Ohio: South-Western. World Economic Forum. 2013. "Global Competitiveness Reports." 
Yates, Jeff, Belinda Creel Davis and Henry R Glick. 2001. "The Politics of Torts: Explaining Litigation Rates in the American States." State Politics and Policy Quarterly, 1:2, 127-143 
Table 1. Basic descriptive statistics for dependent and key independent variables

\begin{tabular}{|c|c|c|c|c|c|c|c|c|c|c|}
\hline Variable & Description & Mean & St. dev. & Min. & $\mathrm{q}_{0.10}$ & $\mathrm{q}_{0.25}$ & $\mathrm{q}_{0.50}$ & $\mathrm{q}_{0.75}$ & $\mathrm{q}_{0.90}$ & Max. \\
\hline \multirow[t]{3}{*}{$L I T$} & $\begin{array}{l}\text { Number of incoming cases } \\
\text { (civil and commercial) per } \\
10,000 \text { inhabitants }\end{array}$ & 240.4 & 159.9 & 17.5 & 53.5 & 114.1 & 223.2 & 328.8 & 436.9 & 955.1 \\
\hline & Between variation & & 144.0 & & & & & & & \\
\hline & Within variation & & 66.5 & & & & & & & \\
\hline \multirow[t]{3}{*}{ PEN } & $\begin{array}{l}\text { Number of pending (or } \\
\text { unresolved) cases per judge }\end{array}$ & 102.4 & 128.3 & 6 & 15 & 29 & 52.5 & 113 & 264 & 644 \\
\hline & Between variation & & 118.8 & & & & & & & \\
\hline & Within variation & & 42.6 & & & & & & & \\
\hline \multirow[t]{3}{*}{$R E S$} & $\begin{array}{l}\text { Number of resolved cases } \\
\text { per judge }\end{array}$ & 132.0 & 92.1 & 10 & 36 & 73 & 101.5 & 172 & 254 & 441 \\
\hline & Between variation & & 84.1 & & & & & & & \\
\hline & Within variation & & 31.0 & & & & & & & \\
\hline \multirow[t]{3}{*}{ IND } & $\begin{array}{l}\text { Judicial independence } \\
\text { score, measured on a 1-7 }\end{array}$ & 4.09 & 1.33 & 2.00 & 2.58 & 2.95 & 3.76 & 5.26 & 6.24 & 6.63 \\
\hline & Between variation & & 1.353 & & & & & & & \\
\hline & Within variation & & 0.296 & & & & & & & \\
\hline
\end{tabular}

Notes: The maximum number of observations (balanced panel) is $N=n \times T=36 \times 4=144$, where $n$ is the number of countries, and $T$ is the number of time periods. The actual number of observations (unbalanced panel) used in the estimations below is $126(\bar{T}=3.5)$. Descriptive statistics are based on the sample effectively used in the estimations. $q_{\tau}$ stands for the $\tau$-th quantile of the observed distribution for each variable. 
Table 2. Results for POLS, RE, and UQR-RE estimators

\begin{tabular}{|c|c|c|c|c|c|c|c|c|c|}
\hline & \multirow{2}{*}{$\begin{array}{l}\text { POLS } \\
\text { Mean }\end{array}$} & \multirow{2}{*}{$\begin{array}{c}\text { RE } \\
\text { Mean }\end{array}$} & \multicolumn{7}{|c|}{ UQR-RE } \\
\hline & & & $q_{0.10}$ & $q_{0.20}$ & $\mathrm{q}_{0.25}$ & $q_{0.50}$ & $q_{0.75}$ & $q_{0.80}$ & $\mathrm{q}_{0.90}$ \\
\hline & (1) & $(2)$ & (3) & (4) & (5) & (6) & (7) & (8) & (9) \\
\hline \multicolumn{10}{|c|}{ A: Estimated coefficients $\left(\widehat{\beta}_{\tau}\right)$} \\
\hline PEN & $\begin{array}{c}1.561^{* *} \\
(0.406)\end{array}$ & $\begin{array}{c}0.728 * * \\
(0.274)\end{array}$ & $\begin{array}{l}-0.480 \\
(0.471)\end{array}$ & $\begin{array}{c}0.303 \\
(0.627)\end{array}$ & $\begin{array}{l}-0.201 \\
(0.437)\end{array}$ & $\begin{array}{c}0.163 \\
(0.429)\end{array}$ & $\begin{array}{c}1.270 \\
(0.816)\end{array}$ & $\begin{array}{c}2.477^{* *} \\
(0.707)\end{array}$ & $\begin{array}{c}2.059 \\
(1.357)\end{array}$ \\
\hline RES & $\begin{array}{l}1.741^{* *} \\
(0.226)\end{array}$ & $\begin{array}{c}1.997^{* *} \\
(0.186)\end{array}$ & $\begin{array}{c}0.369 \\
(0.254)\end{array}$ & $\begin{array}{l}0.535^{*} \\
(0.253)\end{array}$ & $\begin{array}{c}0.361^{+} \\
(0.203)\end{array}$ & $\begin{array}{c}1.305^{* *} \\
(0.469)\end{array}$ & $\begin{array}{c}1.633^{* *} \\
(0.492)\end{array}$ & $\begin{array}{c}2.047^{* *} \\
(0.474)\end{array}$ & $\begin{array}{c}3.070 * * \\
(0.881)\end{array}$ \\
\hline$P E N \times R E S$ & $\begin{array}{c}-0.0022^{* *} \\
(0.0005)\end{array}$ & $\begin{array}{c}-0.0013^{* *} \\
(0.0004)\end{array}$ & $\begin{array}{l}-0.0009 \\
(0.0006)\end{array}$ & $\begin{array}{l}-0.0008 \\
(0.0005)\end{array}$ & $\begin{array}{l}-0.0006 \\
(0.0004)\end{array}$ & $\begin{array}{c}-0.0024 * * \\
(0.0008)\end{array}$ & $\begin{array}{c}0.0012 \\
(0.0008)\end{array}$ & $\begin{array}{c}0.0007 \\
(0.0009)\end{array}$ & $\begin{array}{c}0.0000 \\
(0.0016)\end{array}$ \\
\hline IND & $\begin{array}{c}10.66 \\
(12.52)\end{array}$ & $\begin{array}{l}-7.414 \\
(10.36)\end{array}$ & $\begin{array}{l}-5.265 \\
(29.18)\end{array}$ & $\begin{array}{c}8.404 \\
(28.32)\end{array}$ & $\begin{array}{l}-20.08 \\
(23.52)\end{array}$ & $\begin{array}{c}-60.11^{* *} \\
(21.09)\end{array}$ & $\begin{array}{c}5.445 \\
(24.95)\end{array}$ & $\begin{array}{c}25.59 \\
(22.28)\end{array}$ & $\begin{array}{l}-0.752 \\
(35.58)\end{array}$ \\
\hline$P E N \times I N D$ & $\begin{array}{c}-0.338^{* *} \\
(0.102)\end{array}$ & $\begin{array}{c}-0.183^{* *} \\
(0.055)\end{array}$ & $\begin{array}{c}0.214 \\
(0.159)\end{array}$ & $\begin{array}{l}-0.039 \\
(0.212)\end{array}$ & $\begin{array}{c}0.116 \\
(0.144)\end{array}$ & $\begin{array}{c}0.172 \\
(0.119)\end{array}$ & $\begin{array}{l}-0.412 \\
(0.261)\end{array}$ & $\begin{array}{c}-0.766^{* *} \\
(0.187)\end{array}$ & $\begin{array}{c}-0.724^{*} \\
(0.322)\end{array}$ \\
\hline$G D P P C$ & $\begin{array}{c}18.14 \\
(24.80)\end{array}$ & $\begin{array}{c}30.39 \\
(24.62)\end{array}$ & $\begin{array}{l}-60.63 \\
(40.12)\end{array}$ & $\begin{array}{l}-1.668 \\
(43.57)\end{array}$ & $\begin{array}{l}-9.557 \\
(35.44)\end{array}$ & $\begin{array}{c}18.08 \\
(59.25)\end{array}$ & $\begin{array}{c}74.99 \\
(83.58)\end{array}$ & $\begin{array}{c}71.19 \\
(56.29)\end{array}$ & $\begin{array}{l}157.1^{*} \\
(69.40)\end{array}$ \\
\hline GDPPC square & $\begin{array}{l}-0.711 \\
(2.511)\end{array}$ & $\begin{array}{l}-2.526 \\
(2.386)\end{array}$ & $\begin{array}{c}5.717 \\
(3.928)\end{array}$ & $\begin{array}{c}0.478 \\
(4.231)\end{array}$ & $\begin{array}{c}1.463 \\
(3.623)\end{array}$ & $\begin{array}{l}-1.627 \\
(5.727)\end{array}$ & $\begin{array}{l}-2.611 \\
(8.089)\end{array}$ & $\begin{array}{l}-7.646 \\
(5.494)\end{array}$ & $\begin{array}{c}-15.27^{*} \\
(6.761)\end{array}$ \\
\hline TIME $\times$ WEST & $\begin{array}{c}-11.39 \\
(9.69)\end{array}$ & $\begin{array}{l}-8.316^{+} \\
(4.868)\end{array}$ & $\begin{array}{c}9.149 \\
(6.503)\end{array}$ & $\begin{array}{c}13.27 \\
(10.26)\end{array}$ & $\begin{array}{c}31.29 \\
(21.51)\end{array}$ & $\begin{array}{c}11.75 \\
(17.39)\end{array}$ & $\begin{array}{l}-14.65 \\
(13.10)\end{array}$ & $\begin{array}{l}-16.41 \\
(13.90)\end{array}$ & $\begin{array}{l}-31.55 \\
(24.75)\end{array}$ \\
\hline TIME $\times E A S T$ & $\begin{array}{c}5.981 \\
(9.359)\end{array}$ & $\begin{array}{c}7.336^{+} \\
(3.958)\end{array}$ & $\begin{array}{c}14.22 \\
(8.720)\end{array}$ & $\begin{array}{c}3.629 \\
(12.36)\end{array}$ & $\begin{array}{l}-1.216 \\
(3.213)\end{array}$ & $\begin{array}{c}7.142 \\
(11.06)\end{array}$ & $\begin{array}{c}32.55^{+} \\
(17.32)\end{array}$ & $\begin{array}{l}-23.73 \\
(14.99)\end{array}$ & $\begin{array}{l}-7.671 \\
(19.03)\end{array}$ \\
\hline TIME $\times$ NORTH & $\begin{array}{c}-30.77^{* *} \\
(9.87)\end{array}$ & $\begin{array}{c}0.269 \\
(2.872)\end{array}$ & $\begin{array}{c}6.955 \\
(30.72)\end{array}$ & $\begin{array}{c}-62.23^{* *} \\
(19.89)\end{array}$ & $\begin{array}{c}-34.90 * \\
(17.45)\end{array}$ & $\begin{array}{c}6.875 \\
(5.434)\end{array}$ & $\begin{array}{c}5.875 \\
(7.170)\end{array}$ & $\begin{array}{c}3.084 \\
(8.450)\end{array}$ & $\begin{array}{c}2.061 \\
(12.91)\end{array}$ \\
\hline TIME $\times$ SOUTH & $\begin{array}{l}-2.362 \\
(14.44)\end{array}$ & $\begin{array}{l}-14.30 \\
(9.537)\end{array}$ & $\begin{array}{c}7.939 \\
(6.657)\end{array}$ & $\begin{array}{c}14.38 \\
(10.51)\end{array}$ & $\begin{array}{c}1.253 \\
(5.413)\end{array}$ & $\begin{array}{c}-23.90^{+} \\
(13.75)\end{array}$ & $\begin{array}{c}13.28 \\
(26.54)\end{array}$ & $\begin{array}{c}17.87 \\
(28.78)\end{array}$ & $\begin{array}{l}-63.22 \\
(49.32)\end{array}$ \\
\hline$R$-square & 0.663 & 0.613 & 0.226 & 0.412 & 0.301 & 0.422 & 0.452 & 0.561 & 0.430 \\
\hline No. of obs. & 126 & 126 & 126 & 126 & 126 & 126 & 126 & 126 & 126 \\
\hline No. of countries & 36 & 36 & 36 & 36 & 36 & 36 & 36 & 36 & 36 \\
\hline \multicolumn{10}{|c|}{ B: Estimated effects of PEN on LIT, evaluated at selected levels of RES and IND $\left(\hat{\eta}_{\tau}\right)$} \\
\hline \multicolumn{10}{|l|}{$\underline{\text { Low } R E S=36}$} \\
\hline Low $/ N D=2.58$ & $\begin{array}{c}0.603^{* *} \\
(0.181)\end{array}$ & $\begin{array}{c}0.211^{+} \\
(0.125)\end{array}$ & $\begin{array}{c}0.038 \\
(0.108)\end{array}$ & $\begin{array}{c}0.174 \\
(0.139)\end{array}$ & $\begin{array}{c}0.078 \\
(0.107)\end{array}$ & $\begin{array}{c}0.521^{* *} \\
(0.152)\end{array}$ & $\begin{array}{c}0.250 \\
(0.218)\end{array}$ & $\begin{array}{l}0.523^{+} \\
(0.536)\end{array}$ & $\begin{array}{c}0.190 \\
(0.536)\end{array}$ \\
\hline Median IND=3.76 & $\begin{array}{c}0.211 \\
(0.152)\end{array}$ & $\begin{array}{l}-0.004 \\
(0.118)\end{array}$ & $\begin{array}{c}0.290^{+} \\
(0.161)\end{array}$ & $\begin{array}{c}0.178 \\
(0.215)\end{array}$ & $\begin{array}{c}0.215 \\
(0.142)\end{array}$ & $\begin{array}{c}0.725^{* *} \\
(0.135)\end{array}$ & $\begin{array}{l}-0.237 \\
(0.274)\end{array}$ & $\begin{array}{l}-0.381 \\
(0.298)\end{array}$ & $\begin{array}{c}-0.664^{*} \\
(0.291)\end{array}$ \\
\hline High IND=6.24 & $\begin{array}{c}-0.627^{*} \\
(0.313)\end{array}$ & $\begin{array}{c}-0.457^{*} \\
(0.195)\end{array}$ & $\begin{array}{c}0.820 \\
(0.533)\end{array}$ & $\begin{array}{c}0.031 \\
(0.715)\end{array}$ & $\begin{array}{c}0.503 \\
(0.477)\end{array}$ & $\begin{array}{c}1.152^{* *} \\
(0.369)\end{array}$ & $\begin{array}{l}-1.260 \\
(0.866)\end{array}$ & $\begin{array}{c}-2.282^{* *} \\
(0.619)\end{array}$ & $\begin{array}{c}-2.461^{* *} \\
(0.774)\end{array}$ \\
\hline \multicolumn{10}{|l|}{ High RES $=254$} \\
\hline Low $/ N D=2.58$ & $\begin{array}{c}0.126 \\
(0.119)\end{array}$ & $\begin{array}{l}-0.064 \\
(0.113)\end{array}$ & $\begin{array}{l}-0.164 \\
(0.122)\end{array}$ & $\begin{array}{l}-0.002 \\
(0.132)\end{array}$ & $\begin{array}{l}-0.043 \\
(0.123)\end{array}$ & $\begin{array}{c}0.002 \\
(0.144)\end{array}$ & $\begin{array}{c}0.521^{* *} \\
(0.185)\end{array}$ & $\begin{array}{c}0.665^{* *} \\
(0.205)\end{array}$ & $\begin{array}{c}0.193 \\
(0.388)\end{array}$ \\
\hline Median IND=3.76 & $\begin{array}{c}-0.273^{*} \\
(0.130)\end{array}$ & $\begin{array}{c}-0.280^{*} \\
(0.117)\end{array}$ & $\begin{array}{c}0.088 \\
(0.111)\end{array}$ & $\begin{array}{l}-0.048 \\
(0.158)\end{array}$ & $\begin{array}{c}0.094 \\
(0.103)\end{array}$ & $\begin{array}{c}0.206 \\
(0.190)\end{array}$ & $\begin{array}{c}0.034 \\
(0.304)\end{array}$ & $\begin{array}{l}-0.239 \\
(0.284)\end{array}$ & $\begin{array}{c}-0.662^{+} \\
(0.353)\end{array}$ \\
\hline High IND=6.24 & $\begin{array}{c}-1.111^{* *} \\
(0.343)\end{array}$ & $\begin{array}{c}-0.732^{* *} \\
(0.209)\end{array}$ & $\begin{array}{c}0.618 \\
(0.485)\end{array}$ & $\begin{array}{l}-0.145 \\
(0.670)\end{array}$ & $\begin{array}{c}0.381 \\
(0.437)\end{array}$ & $\begin{array}{c}0.633 \\
(0.443)\end{array}$ & $\begin{array}{l}-0.989 \\
(0.912)\end{array}$ & $\begin{array}{c}-2.140 * * \\
(0.693)\end{array}$ & $\begin{array}{c}-2.458^{*} \\
(1.004)\end{array}$ \\
\hline
\end{tabular}

Notes: Cluster-robust standard errors are given in parentheses. The selected percentiles of RES and IND are the 10th, 50th, and 90th percentiles of their distributions in the estimation sample. For POLS and RE, both $\widehat{\beta}_{\tau}$ and $\hat{\eta}_{\tau}$ are constants $\left(\widehat{\beta}_{\tau}=\widehat{\beta}_{\text {and }} \hat{\eta}_{\tau}=\hat{\eta}\right)$. Estimated intercepts have not been reported to save space.

+ Significant at $10 \%$ level; * significant at $5 \%$ level; ** significant at $1 \%$ level. 
Table 3. Tests for equality of estimated effects at different quantiles of LIT distribution

\begin{tabular}{|c|c|c|c|}
\hline & $\begin{array}{c}\hat{\eta}_{0.50}-\hat{\eta}_{0.10} \\
\text { Low-end } \\
\text { heterogeneity }\end{array}$ & $\begin{array}{c}\hat{\eta}_{0.90}-\hat{\eta}_{0.50} \\
\text { High-end } \\
\text { heterogeneity }\end{array}$ & $\begin{array}{c}\hat{\eta}_{0.90}-\hat{\eta}_{0.10} \\
\text { Overall } \\
\text { heterogeneity }\end{array}$ \\
\hline & (1) & (2) & (3) \\
\hline \multicolumn{4}{|l|}{ Low RES $=36$} \\
\hline Low $I N D=2.58$ & $\begin{array}{c}0.483 \\
(0.309)\end{array}$ & $\begin{array}{l}-0.331 \\
(0.744)\end{array}$ & $\begin{array}{c}0.153 \\
(0.848)\end{array}$ \\
\hline Median IND=3.76 & $\begin{array}{c}0.435 \\
(0.423)\end{array}$ & $\begin{array}{l}-1.389^{+} \\
(0.856)\end{array}$ & $\begin{array}{l}-0.954 \\
(0.750)\end{array}$ \\
\hline High IND=6.24 & $\begin{array}{c}0.332 \\
(0.591)\end{array}$ & $\begin{array}{c}-3.613^{* *} \\
(0.004)\end{array}$ & $\begin{array}{c}-3.281^{* *} \\
(0.009)\end{array}$ \\
\hline \multicolumn{4}{|l|}{ High $R E S=254$} \\
\hline Low $I N D=2.58$ & $\begin{array}{c}0.167 \\
(0.647)\end{array}$ & $\begin{array}{c}0.191 \\
(0.776)\end{array}$ & $\begin{array}{c}0.358 \\
(0.586)\end{array}$ \\
\hline Median IND=3.76 & $\begin{array}{c}0.118 \\
(0.247)\end{array}$ & $\begin{array}{l}-0.867 \\
(0.589)\end{array}$ & $\begin{array}{l}-0.750 \\
(0.692)\end{array}$ \\
\hline High IND=6.24 & $\begin{array}{c}0.015 \\
(0.978)\end{array}$ & $\begin{array}{c}-3.091^{* *} \\
(0.004)\end{array}$ & $\begin{array}{c}-3.076^{* *} \\
(0.005)\end{array}$ \\
\hline
\end{tabular}

Note: Bootstrapping (100 replications) are used to provide standard-error estimates, which are given in parentheses. The selected percentiles of RES and IND are the 10th, 50th, and 90th percentiles of their distributions in the estimation sample.

+ Significant at $10 \%$ level; * significant at $5 \%$ level; ${ }^{* *}$ significant at $1 \%$ level. 
Table 4. Results for POLS1, CRE, and UQR-CRE estimators

\begin{tabular}{|c|c|c|c|c|c|c|c|c|c|}
\hline & \multirow{2}{*}{$\begin{array}{l}\text { POLS1 } \\
\text { Mean } \\
\end{array}$} & \multirow{2}{*}{$\begin{array}{c}\text { CRE } \\
\text { Mean }\end{array}$} & \multicolumn{7}{|c|}{ UQR-CRE } \\
\hline & & & $\mathrm{q}_{0.10}$ & $\mathrm{q}_{0.20}$ & $\mathrm{q}_{0.25}$ & $\mathrm{q}_{0.50}$ & $\mathrm{q}_{0.75}$ & $\mathrm{q}_{0.80}$ & $\mathrm{q}_{0.90}$ \\
\hline & $(1)$ & $(2)$ & (3) & (4) & (5) & $(6)$ & $(7)$ & (8) & (9) \\
\hline \multicolumn{10}{|c|}{ Estimated effects of PEN on LIT, evaluated at selected levels of RES and IND $\left(\hat{\eta}_{\tau}\right)$} \\
\hline \multicolumn{10}{|l|}{ Low $R E S=36$} \\
\hline Low IND=2.58 & $\begin{array}{c}0.407^{+} \\
(0.223)\end{array}$ & $\begin{array}{c}0.205 \\
(0.128)\end{array}$ & $\begin{array}{c}0.100 \\
(0.111)\end{array}$ & $\begin{array}{c}0.151^{+} \\
(0.087)\end{array}$ & $\begin{array}{c}0.167 \\
(0.105)\end{array}$ & $\begin{array}{c}0.520 * * \\
(0.105)\end{array}$ & $\begin{array}{c}0.262 \\
(0.235)\end{array}$ & $\begin{array}{c}0.552 \\
(0.337)\end{array}$ & $\begin{array}{c}0.594 \\
(0.705)\end{array}$ \\
\hline Median IND=3.76 & $\begin{array}{l}-0.004 \\
(0.200)\end{array}$ & $\begin{array}{l}-0.006 \\
(0.136)\end{array}$ & $\begin{array}{c}0.061 \\
(0.126)\end{array}$ & $\begin{array}{c}0.008 \\
(0.103)\end{array}$ & $\begin{array}{c}0.027 \\
(0.148)\end{array}$ & $\begin{array}{c}0.639 * * \\
(0.135)\end{array}$ & $\begin{array}{c}0.012 \\
(0.323)\end{array}$ & $\begin{array}{l}-0.242 \\
(0.370)\end{array}$ & $\begin{array}{l}-0.037 \\
(0.672)\end{array}$ \\
\hline High IND=6.24 & $\begin{array}{c}-0.869^{+} \\
(0.460)\end{array}$ & $\begin{array}{c}-0.451^{+} \\
(0.261)\end{array}$ & $\begin{array}{l}-0.020 \\
(0.394)\end{array}$ & $\begin{array}{l}-0.291 \\
(0.404)\end{array}$ & $\begin{array}{l}-0.266 \\
(0.548)\end{array}$ & $\begin{array}{c}0.890^{+} \\
(0.514)\end{array}$ & $\begin{array}{l}-0.512 \\
(1.000)\end{array}$ & $\begin{array}{c}-1.909 * \\
(0.848)\end{array}$ & $\begin{array}{l}-1.364 \\
(0.995)\end{array}$ \\
\hline \multicolumn{10}{|l|}{ High RES $=254$} \\
\hline Low IND=2.58 & $\begin{array}{l}-0.185 \\
(0.215)\end{array}$ & $\begin{array}{l}-0.079 \\
(0.134)\end{array}$ & $\begin{array}{l}-0.113 \\
(0.113)\end{array}$ & $\begin{array}{l}-0.125 \\
(0.115)\end{array}$ & $\begin{array}{l}-0.096 \\
(0.134)\end{array}$ & $\begin{array}{l}-0.218 \\
(0.173)\end{array}$ & $\begin{array}{c}0.518^{+} \\
(0.286)\end{array}$ & $\begin{array}{l}0.692^{*} \\
(0.352)\end{array}$ & $\begin{array}{c}1.088 \\
(0.753)\end{array}$ \\
\hline Median IND=3.76 & $\begin{array}{c}-0.596^{*} \\
(0.249)\end{array}$ & $\begin{array}{c}-0.290^{+} \\
(0.158)\end{array}$ & $\begin{array}{l}-0.152 \\
(0.157)\end{array}$ & $\begin{array}{l}-0.268 \\
(0.174)\end{array}$ & $\begin{array}{l}-0.236 \\
(0.192)\end{array}$ & $\begin{array}{l}-0.098 \\
(0.245)\end{array}$ & $\begin{array}{c}0.269 \\
(0.408)\end{array}$ & $\begin{array}{l}-0.101 \\
(0.486)\end{array}$ & $\begin{array}{c}0.457 \\
(0.785)\end{array}$ \\
\hline High IND=6.24 & $\begin{array}{c}-1.460 * * \\
(0.536)\end{array}$ & $\begin{array}{c}-0.735^{*} \\
(0.292)\end{array}$ & $\begin{array}{l}-0.233 \\
(0.427)\end{array}$ & $\begin{array}{l}-0.567 \\
(0.460)\end{array}$ & $\begin{array}{l}-0.529 \\
(0.576)\end{array}$ & $\begin{array}{c}0.152 \\
(0.595)\end{array}$ & $\begin{array}{l}-0.255 \\
(1.066)\end{array}$ & $\begin{array}{c}-1.769^{+} \\
(1.001)\end{array}$ & $\begin{array}{l}-0.870 \\
(1.121)\end{array}$ \\
\hline
\end{tabular}

Notes: Time averages are also included in POLS1. Cluster-robust standard errors are given in parentheses. The selected percentiles of RES and IND are the 10th, 50th, and 90th percentiles of their distributions in the estimation sample. For POLS1 and CRE, the " $\eta$ " _ $\tau$ are constants, by assumption (" $\left.\eta " \wedge \_\tau=" \eta " \wedge\right)$.

+ Significant at $10 \%$ level; * significant at 5\% level; ** significant at $1 \%$ level. 
Table 5. Estimates from linear dynamic panel data (Arellano-Bover) model

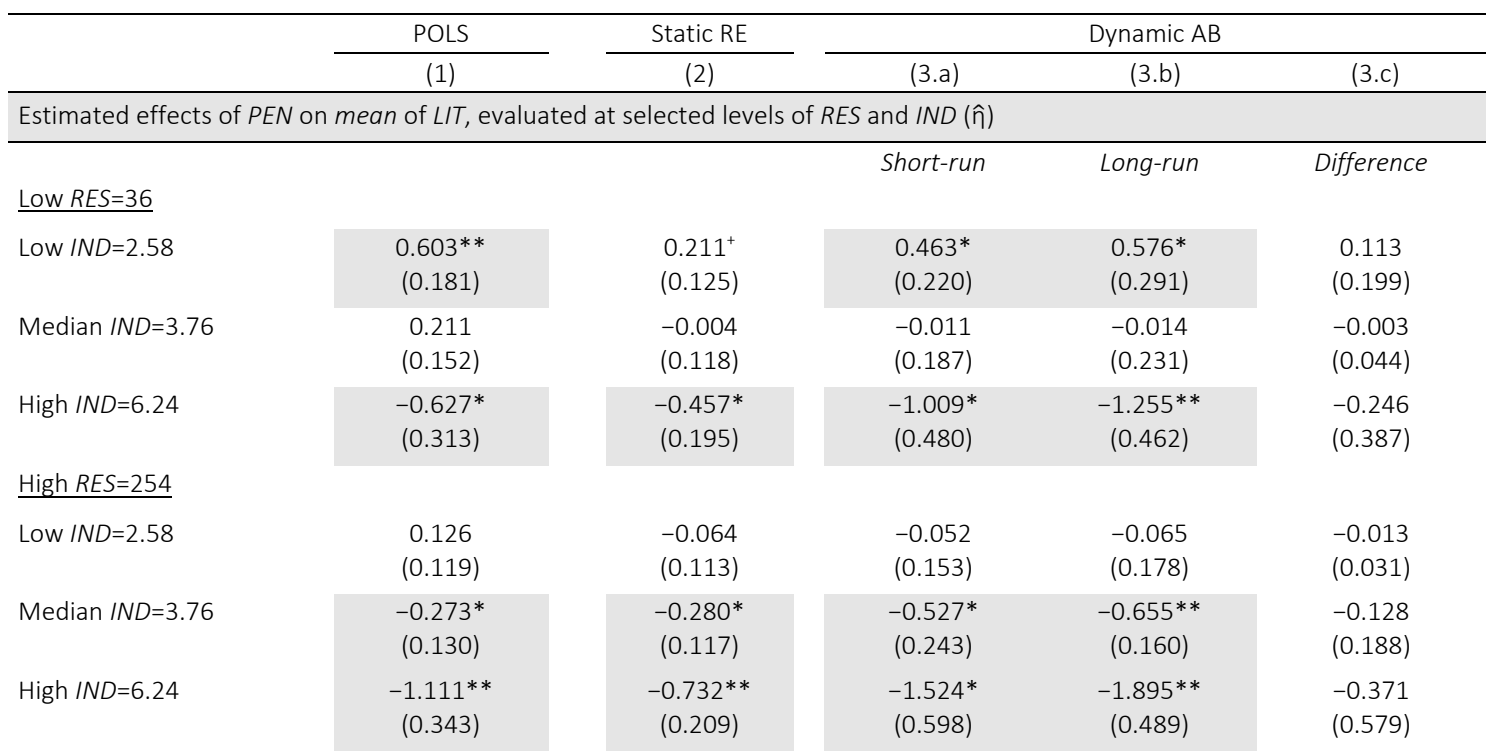

Notes: For convenience, the results in columns (1) and (2) are replications of those reported in in columns (1) and (2) of Table 2. The dynamic AB panel data model is estimated using Stata's xtabond2 command (with two-step option), where we used the augmented version of the Arellano and Bond (1991) "difference-GMM" estimator outlined by Arellano and Bover (1995), which is known as the "system-GMM" estimator. (We also used Stata's collapse sub-option because in small samples it can avoid the bias that arises as the number of instruments climbs toward the number of observations; when instruments are many, they tend to over-fit the instrumented variables and bias the results toward those of OLS/GLS.) See also Roodman (2009). The coefficient on the lagged dependent variable $L I T(t-1)$ is estimated at around 0.20 , which, however, is statistically not significant different from zero, with $p$ value $=0.290$ (though the coefficient is significantly different from 1 ). The results from the AB model should be taken with some care, since the $A B$ model diagnostics are not in accordance with hopes; that is, the Arellano-Bond test of zero autocorrelation of the firstdifferenced errors could not be rejected, with $p$-value $=0.863$, while the Hansen test for overidentification (no misspecification) is rejected, with $p$-value $=0.041$.

+ Significant at $10 \%$ level; * significant at $5 \%$ level; ** significant at $1 \%$ level. 
Figure 1. Time-averaged country-level litigation rates and pending cases

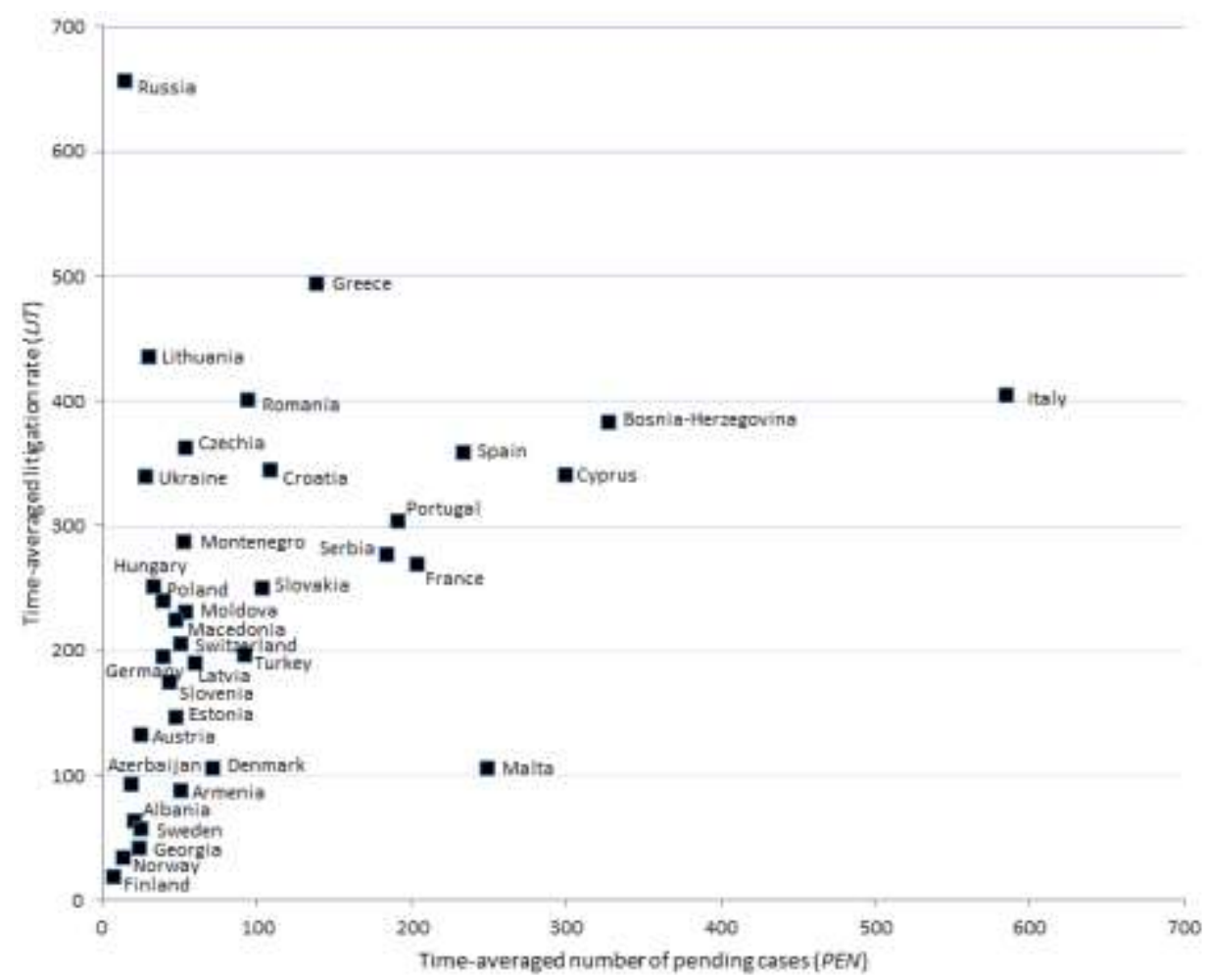

Note: The positive correlation between (time-averaged) LIT and PEN is 0.361 , with $p<0.001$. 
Figure 2. Quantile plots showing the effects of PEN on LIT for UQR-RE

A: Evaluated at low RES and low/high IND

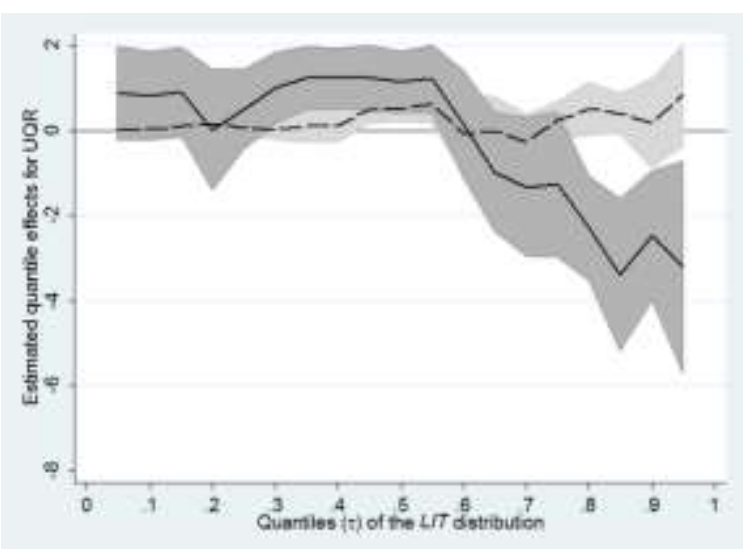

B: Evaluated at high RES and low/high IND

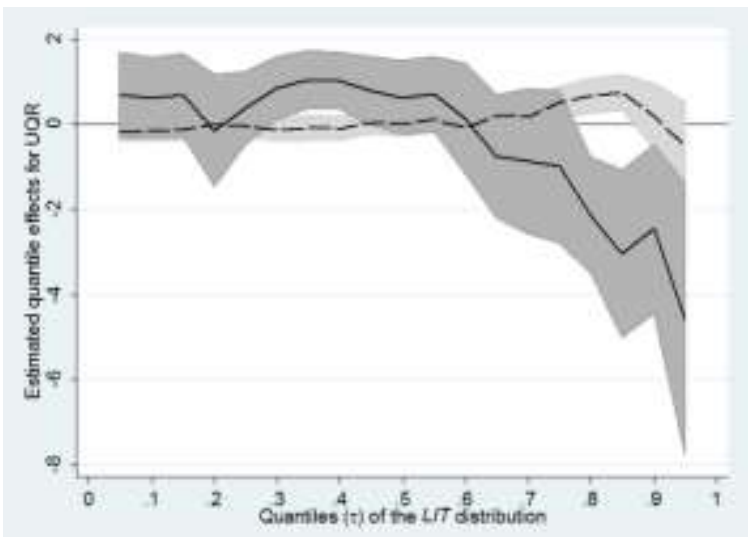

Notes: Panel A is for low RES (36), while panel B is for high RES (254). The dashed and solid curves are for low IND (2.58) and high IND (6.24), respectively. The vertical axis indicates the values of the estimated quantile effects of $P E N$; the horizontal axis marks the quantiles of the LIT distribution $(\tau=0.05,0.10, \ldots, 0.95)$. The shaded areas represent the corresponding $95 \%$ point-wise confidence intervals. 
Figure 3. Simulated impact of one-half standard deviation increase in PEN on LIT distribution

A: Evaluated at low RES and high IND

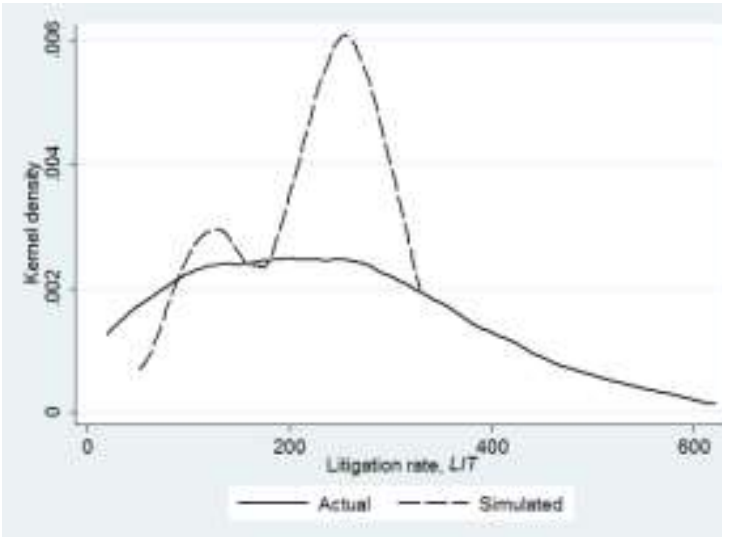

B: Evaluated at high RES and high IND

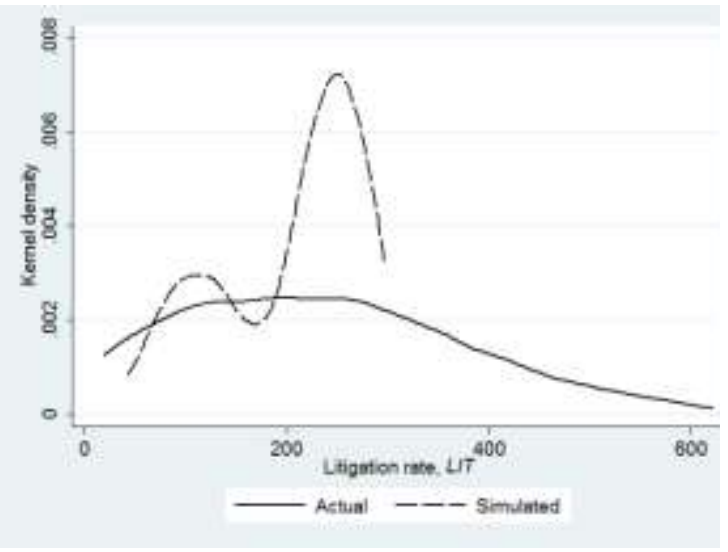

Notes: The graphs show estimated kernel density functions of the LIT distribution "before" (solid curves) and "after" (dashed curves) the one-half standard deviation increase in PEN, ceteris paribus. The kernel density estimates are constructed for the 97 percentiles ( $\tau=0.02,0.03, \ldots, 0.98)$ of the LIT distribution. The standard deviation of PEN in the estimation sample is equal to 128.3 (Table 1). 
Figure 4. Quantile plots showing the effects of PEN on LIT for UQR-CRE

A: Evaluated at low RES and low/high IND

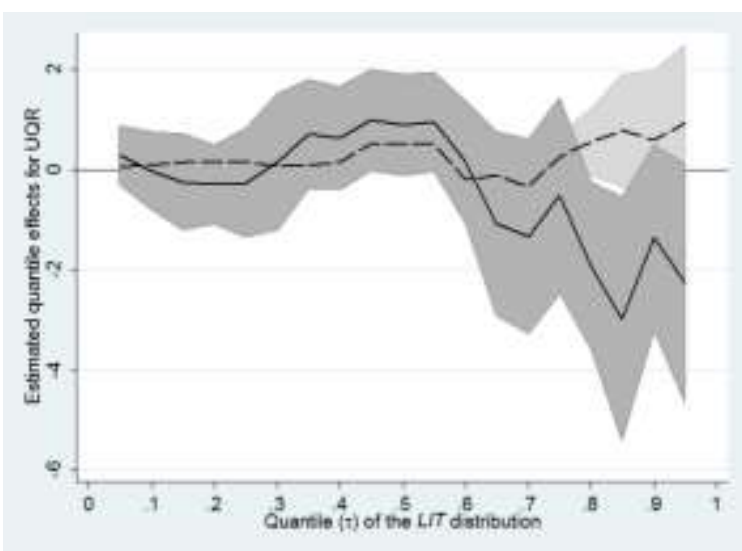

B: Evaluated at high RES and low/high IND

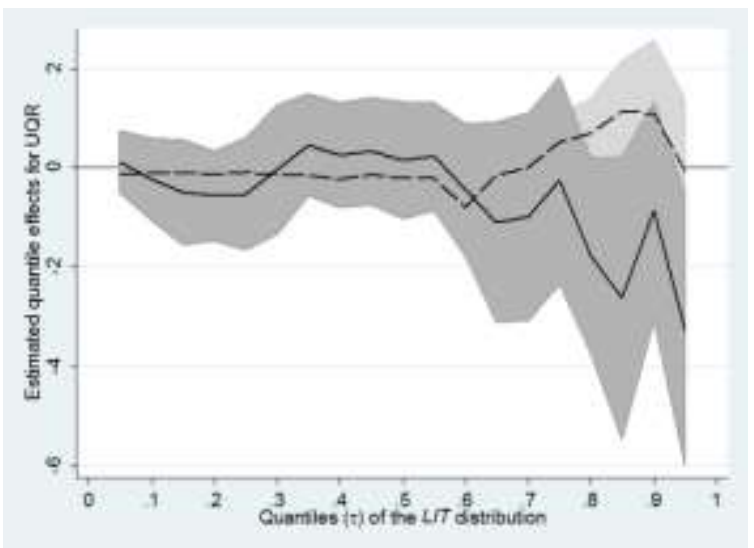

Notes: Panel A is for low RES (36), while panel B is for high RES (254). The dashed and solid curves are for low IND (2.58) and high IND (6.24), respectively. The vertical axis indicates the values of the estimated quantile effects of $P E N$; the horizontal axis marks the quantiles of the $L I T$ distribution $(\tau=0.05,0.10, \ldots, 0.95)$. The shaded areas represent the corresponding $95 \%$ point-wise confidence intervals. 
Appendix 1: List of Countries

\begin{tabular}{|c|c|c|c|c|}
\hline Countries $(n=36)$ & $\begin{array}{l}\text { Lower } 25 \% \text { tail } \\
\text { (lightly litigious) }\end{array}$ & $\begin{array}{l}\text { Middle } 50 \% \text { range } \\
\text { (moderately litigious) }\end{array}$ & $\begin{array}{l}\text { Upper 25\% tail } \\
\text { (heavily litigious) }\end{array}$ & Region \\
\hline Albania & $x$ & & & East \\
\hline Armenia & $x$ & & & East \\
\hline Austria & $x$ & & & West \\
\hline Azerbaijan & $x$ & & & East \\
\hline Bosnia-Herzegovina & & & $x$ & East \\
\hline Croatia & & $x$ & & East \\
\hline Cyprus & & $x$ & & South \\
\hline Czech Rep. & & & & East \\
\hline Denmark & $x$ & & & North \\
\hline Estonia & & $x$ & & East \\
\hline Finland & $x$ & & & North \\
\hline France & & X & & West \\
\hline Georgia & $x$ & & & East \\
\hline Germany & & $x$ & & West \\
\hline Greece & & & X & South \\
\hline Hungary & & $x$ & & East \\
\hline Italy & & & $x$ & South \\
\hline Latvia & & $x$ & & East \\
\hline Lithuania & & & $x$ & East \\
\hline Malta & $x$ & & & South \\
\hline Moldova & & $x$ & & East \\
\hline Montenegro & & $x$ & & East \\
\hline Norway & $x$ & & & North \\
\hline Poland & & $x$ & & East \\
\hline Portugal & & $x$ & & South \\
\hline Romania & & & $x$ & East \\
\hline Russian Federation & & & $x$ & East \\
\hline Serbia & & $x$ & & East \\
\hline Slovakia & & $x$ & & East \\
\hline Slovenia & & $x$ & & East \\
\hline Spain & & $x$ & & South \\
\hline Sweden & $x$ & & & North \\
\hline Switzerland & & $x$ & & West \\
\hline Macedonia & & $x$ & & South \\
\hline Turkey & & $x$ & & South \\
\hline Ukraine & & $x$ & & East \\
\hline
\end{tabular}

Note: An " $\mathrm{X}$ " indicates to which segment of the litigation-rate distribution a country belongs. 